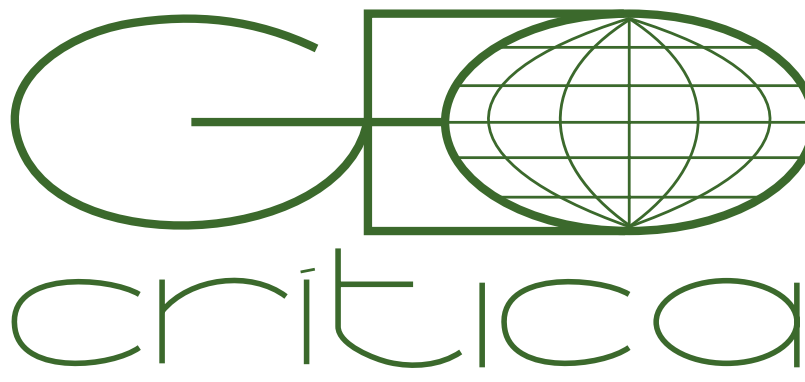

\section{Scripta Nova}

Revista Electrónica de Geografía y Ciencias Sociales Universitat de Barcelona

15 de Agosto de 2020

\title{
CONMEMORACIÓN, PATRIMONIO Y ESPACIO. LOS LUGARES DE MEMORIA HISTÓRICA Y DEMOCRÁTICA DE ANDALUCÍA
}

\author{
Víctor Fernández Salinas \\ salinas@us.es \\ Rocío Silva Pérez \\ rsilva@us.es \\ Universidad de Sevilla
}

Recibido: 23 junio 2019; Devuelto para correcciones: 28 noviembre 2019; Aceptado: 25 diciembre 2019

\begin{abstract}
Conmemoración, patrimonio y espacio. Los lugares de memoria histórica y democrática de Andalucía (Resumen)

La memoria histórica en Andalucía, nacida de una reivindicación de justicia y reparación a las víctimas de la Guerra Civil y el franquismo, ha experimentado en los últimos años un recorrido que la aproxima al marco conceptual del patrimonio cultural. Además, paralelamente, esta memoria ha encontrado en el espacio un recurso en el que argumentar y tutelar su mensaje. Este trabajo pretende mostrar cómo este proceso no es, ni claro en lo conceptual, ni sencillo en su implementación. Para ello analiza los reconocimientos espaciales que ha tenido la memoria histórica en Andalucía (primero Lugares de Memoria Histórica y después Lugares de Memoria Democrática), así como las distintas consideraciones espaciales asociadas que merecen tales distinciones. Como resultado, además de la reflexión general desde el punto de vista espacial del proceso, se aportan propuestas que mejoren la inclusión en el ámbito patrimonial del legado de esta memoria.
\end{abstract}

Palabras clave: Memoria histórica, patrimonio, Lugares de Memoria Histórica de Andalucía, Lugares de Memoria Democrática de Andalucía, Víctimas.

\section{Commemoration, Heritage and Space. The Sites of Historical and Democratic Memory in Andalusia}

Historical memory in Andalusia, born of a claim of justice and redress to the victims of the Civil War and Franco dictatorship period, has opened in recent years a path that brings it closer to the conceptual framework of cultural heritage. In addition, this memory has found in space a resource in which to argue and protect its message. This paper tries to show how this process is not, nor clear in the conceptual carácter, nor simple in its implementation,. To do this, it analyzes the spatial recognitions that historical memory has had in Andalusia (first Places of Historical Memory and later Places of Democratic Memory), as well as the different associated spatial considerations that deserve such acknowledgments. In addition to the general reflection from the spatial point of view of the process, the article make forward several proposals aiming at improving the inclusion in the patrimonial field of the legacy of this historical memory.

Key words: Historical memory, heritage, Historial Memory Sites, Democratic Memory Sites, Andalucía. 
La conmemoración de hechos luctuosos del pasado, pero con valor simbólico e identitario en el presente, es un aspecto generalizado en casi todas las sociedades; pero esta premisa, con escasas disidencias en buena parte de los países del planeta ${ }^{1}$, dista de ser un hecho socialmente convenido en España, donde el período de la Transición tras el franquismo, que tantos aciertos tuvo para la modernización democrática del país, dejó al margen, o en todo caso muy solapada, la aceptación de la memoria histórica de los vencidos ${ }^{2}$. Esto se ha traducido ya entrado el siglo XXI en un lento pero amplio movimiento a partir de las reivindicaciones de asociaciones de familiares afectados para, no solo exhumar a personas ajusticiadas, sino para revisar los hechos históricos; lograr el derecho a la justicia, si bien en términos simbólicos; y reparar a las víctimas 3 . Se trata de un tema candente que permanece sin solución definitiva a finales del segundo decenio del nuevo siglo ${ }^{4}$.

Un aspecto clave de este proceso es la importancia que asume el espacio, el lugar, como repositorio de la memoria de los hechos del pasado; por eso es frecuente que las leyes y programas que tratan de desagraviar y resarcir a las víctimas tengan un importante contenido de interés geográfico en relación con sus lugares de referencia. El dónde no es algo aleatorio o secundario, sino que, borradas o enterradas a menudo las huellas de los episodios que allí se produjeron, el espacio se convierte en lugar connotado y cargado de significados. Los lugares de memoria histórica, en consecuencia, son escenarios merecedores de una distinción administrativa que los identifique y proteja. El patrimonio cultural, con sus cambios profundos, su generosidad en el entendimiento de aquello que lo conforma y su anclaje en el espacio, se constituye así en su ámbito de referencia directo. Pero el registro patrimonial se reclama desde la memoria histórica y no desde el patrimonio propiamente dicho 5 . Esto provoca incertidumbres en la identificación y protección de un patrimonio emergente del que no se tiene, ni mucho conocimiento, ni práctica en su tutela y gestión.

En Andalucía y alentada desde el poder legislativo y ejecutivo regional por partidos de izquierda, especialmente por el Partido Socialista Obrero Español (PSOE), que dirigió hasta 2019 el gobierno, la memoria histórica alcanza carácter normativo ya en el siglo XxI, aunque durante los primeros años tenía como objeto prioritario proporcionar indemnizaciones a las víctimas y sus familiares. La incorporación oficial del espacio como referente de la conmemoración se produce a partir de 2011 y tiene dos textos clave:

- El Decreto 264/2011, por el que se crean y regulan los Lugares de Memoria Histórica de Andalucía y su catálogo.

- La Ley 2/2017 de Memoria Histórica y Democrática de Andalucía, mediante la cual se conceptúa otra figura, los Lugares de Memoria Democrática de An-

\footnotetext{
1 Nora 1989, Sahdra y Ross 2007.

2 Aguilar Fernández 1997, Medina Domínguez 2001.

3 Colmeiro 2011.

4 Yeste 2011.

5 Bortolotto 2014, Méndez, 2000.
} 
dalucía, y, a su vez, el inventario en el que se recogen los enclaves con esta distinción.

Con esta ley, además de mantener el espacio como referente básico, se acentúa la importancia de estos lugares porque se asimilan a bienes patrimoniales. Este proceso traslada la responsabilidad de la tutela de estos lugares de un ámbito muy político (la Consejería de Presidencia) a otro como el cultural (Consejería de Cultura y Patrimonio Histórico), que se enfrenta en este momento a un triple reto: a) la tutela de estos Lugares de Memoria Democrática, poco o nada conceptuados en su dimensión patrimonial; b) hacerlo en un momento de cambio de directrices patrimoniales, ya que la actual Ley del Patrimonio Histórico Andaluz está en proceso de revisión; y c) llevar a cabo estos retos en un contexto de cambio político importante tras las elecciones andaluzas de diciembre de 2018.

En razón de estos planteamientos, este artículo se propone como objetivos:

- Conocer las leyes y criterios con los que se han identificado los Lugares de Memoria Histórica y los de Memoria Democrática en Andalucía, así como las características tipológicas y de interés geográfico y temporal de estos lugares.

- Clarificar su lectura patrimonial y sus perspectivas en relación con su identificación y protección.

- Revisar las controversias, sobre todo desde la perspectiva espacial, que está provocando la aproximación a los patrones patrimoniales de los Lugares de la Memoria Democrática de Andalucía.

Metodológicamente, este artículo propone partir de la interpretación espacial y patrimonial de la normativa sobre memoria histórica en Andalucía (sobre todo del decreto 264/2011 y de la ley de 2/2017) y de la información recopilada a partir de las fuentes que se detallan en el epígrafe siguiente. Esta interpretación toma como focos de interés:

- Las circunstancias del proceso de declaración de los Lugares de la Memoria Histórica y de los de Memoria Democrática de Andalucía.

- Los agentes que han promovido las declaraciones.

- La tipología (Tabla 1), localización, dominante geográfica (urbana, periurbana o rural); la expresión cartográfica (punto, línea o área) de los Lugares de Memoria Histórica y de los de Memoria Democrática de Andalucía; y la cronología de los hechos reconocidos. A efectos de este trabajo se proponen tres etapas históricas: Guerra Civil ${ }^{6}$ (18 de julio de 1936-1 de abril de 1939), Dictadura (1 de abril de 1939-20 de noviembre de 1975) y Transición (20 de noviembre de 1975-11 de enero de 1982).

6 Aunque la Ley de Memoria Histórica y Democrática incluye en el período objeto de su aplicación la totalidad del lapso republicano, en la praxis solo uno del centenar de lugares de distinta consideración analizados responde a un momento anterior a la Guerra Civil: la casa de Blas Infante en Coria del Río, cuya construcción arranca en 1931 y en la que fue detenido el 2 de agosto de 1936. 
Tabla 1. Tipificación de los Lugares de la Memoria Histórica y de la Democrática de Andalucía

\begin{tabular}{|c|c|}
\hline Tipo & Descripción \\
\hline Memorial & $\begin{array}{l}\text { Espacio que, sin ser escenario de hechos directamente relacionados con la } \\
\text { memoria histórica, han sido seleccionados para conmemorar un hecho del } \\
\text { pasado que sí lo está }\end{array}$ \\
\hline Fosa & $\begin{array}{l}\text { Terreno de inhumación grupal de víctimas de la Guerra Civil y del } \\
\text { franquismo }\end{array}$ \\
\hline Muro & $\begin{array}{l}\text { Lienzo de la pared que rodea un cementerio donde se produjeron } \\
\text { fusilamientos }\end{array}$ \\
\hline Construcción & $\begin{array}{l}\text { Edificio, en su conjunto o en una parte, u obra subterránea, connotados por } \\
\text { algún hecho ligado a la memoria histórica }\end{array}$ \\
\hline Lugar & $\begin{array}{l}\text { Ámbito acotado, de extensión y límites difíciles de precisar a partir de los } \\
\text { registros oficiales. Puede aludir a una esquina, una plaza, un puente, etc. }\end{array}$ \\
\hline Canal & $\begin{array}{l}\text { Este tipo se ajusta al Canal de los Presos, ya que por su escala y dimensión } \\
\text { no concuerda con los contenidos de otros lugares }\end{array}$ \\
\hline Ruta & $\begin{array}{l}\text { Vía de circulación que, o bien posee en sí misma valor como lugar } \\
\text { de memoria, o bien conecta varios lugares de significado histórico } \\
\text { relacionados entre sí }\end{array}$ \\
\hline Zona & $\begin{array}{l}\text { Espacio de extensión variable, pero más amplio que un lugar, que incluye } \\
\text { una pluralidad de testimonios ligados a la memoria histórica }\end{array}$ \\
\hline
\end{tabular}

Fuente: Elaboración propia.

Desde el punto de vista de la adscripción territorial de los lugares objeto de este trabajo, se ha optado por tomar como referencia las provincias y no otras unidades espaciales que podrían parecer más significativas (litoral, vegas, campiñas, sierras, etc.). La razón se basa en que los reconocimientos han tenido un carácter muy político y, en buena medida, sustentado en la estructura administrativa provincial (delegaciones de la consejerías concernidas, de los sindicatos, diputaciones, etc.).

Posteriormente, en las conclusiones, se realizan consideraciones generales sobre el proceso de registro de estos lugares: las sombras y lagunas a las que ha dado lugar y el apunte de algunas estrategias para que el inventario de estos lugares avance hacia la sistematización y, sobre todo, hacia una consideración que permita asimilarlos al resto de los bienes del patrimonio cultural andaluz.

Respecto a las fuentes, además de la bibliografía citada que se relaciona al final del trabajo, se han analizado la legislación pertinente y los documentos que han funcionado como guía en la identificación de los lugares de la Memoria Histórica y de la Democrática de Andalucía. En cuanto a documentos, consultados en internet, se han examinado los disponibles en la web de la Consejería de Cultura y Patrimonio Histórico ${ }^{7}$ :

- Anteproyecto de Ley (de febrero de 2018) por el que se modifica la Ley 14/2007, de 26 de noviembre, de Patrimonio Histórico de Andalucía.

- I Plan Andaluz de Memoria Democrática, 2018-2022 (aprobado en noviembre de 2018).

- Informe de seguimiento de las actuaciones en materia de Memoria Democrática 2017-2018 (de diciembre de 2018).

7 https://www.juntadeandalucia.es/organismos/culturaypatrimoniohistorico.html. 


\section{Marco epistemológico}

\section{Aspectos generales sobre la memoria histórica}

A efectos de este trabajo, la memoria histórica se define como un proceso de reivindicación que proviene de las bases sociales (asociaciones, sindicatos, municipios y particulares), que persigue la revisión de hechos pasados de carácter luctuoso no resueltos por el conjunto de la comunidad y que sirve de instrumento, sobre todo, para la identidad y autoafirmación de esas bases sociales. Aunque se trata de un concepto muy cercano al de historia, posee significados propios que lo diferencian de este término más genérico. Para Pierre Nora la memoria es la vida, siempre en evolución, maleable y afecta a letargos y reactivaciones; en tanto que "la historia es la reconstrucción siempre problemática e incompleta de lo que ya no es" ${ }^{\prime \prime}$. Entre ambos conceptos se pueden establecer puentes, pero cabe recordar que su origen es bien distinto. La memoria es afectiva, producto de la experiencia personal o del grupo al que cohesiona, y se sustenta en buena parte en lo emocional y mágico: la memoria sacraliza. En cambio, la historia, y siguiendo siempre al mismo autor, prosifica, se construye y "pertenece a todos" ${ }^{\prime \prime}$. Se puede hablar de la desconfianza de la historia en la memoria ${ }^{10}$, pero, en los términos de este artículo, esta desconfianza debe conjurarse, o relativizarse, en la asunción del relativismo y subjetividad que los planteamientos patrimoniales y los nuevos patrones de autenticidad han asumido durante los últimos decenios ${ }^{11}$.

Precisamente a efectos de patrimonialización, la memoria histórica, sobre todo tras las dos guerras mundiales, ha incorporado a la conmemoración hechos que implican un dolor colectivo no siempre de fácil consenso social; conmemoración que casi siempre se realiza sobre los mismos espacios de la aflicción y del arrepentimiento que les sirvieron de escenario ${ }^{12}$. Estos reconocimientos, más que manifestaciones sociales muy, o muy poco, alentadas por las instituciones o por colectivos más o menos amplios, se convierten en un derecho en razón de varias resoluciones de la Comisión de Derechos Humanos de las Naciones Unidas (resoluciones sobre impunidad, 2003/72, 2004/72 y 2005/81; y sobre el derecho a la verdad, 2005/66 ${ }^{13}$ ).

Los bienes patrimoniales asociados a esta memoria histórica y su propio proceso de patrimonialización (es decir, cómo derivan hacia hechos con valoraciones institucionales o identitarios) están danto lugar a no pocas dudas en su identificación y reconocimiento. A este respecto, ha surgido una línea de trabajos geográficos, o de interés geográfico, dentro y fuera de España ${ }^{14}$, que contribuye al esclarecimiento de la proyección espacial de esta herencia y que ha llegado a ser denominada geografía de la memoria ${ }^{15}$. Especialmente interesante para esta geografía resulta el llamado lu-

8 Nora 1998, p. 21.

9 Ibidem.

10 Ricoeur, 2004.

11 Arévalo 2010.

12 Huysen 2002.

13 Sauca Cano 2008.

14 Cardesín Díaz 2006, González Vázquez 2016, Hoelscher y Alderman 2004, Lowenthal 1998,

15 García Álvarez 2009, p. 179. 
gar de memoria y todos los conceptos que lo acompañan: «La geografía de la memoria localiza la historia y sus representaciones en el espacio y el paisaje. Contesta a la cuestión de "dónde está la memoria" en términos de lugares y sitios que vacían una cierta visión de la historia en un molde de permanencia conmemorativa»" ${ }^{16}$.

La memoria histórica no es un concepto desligado del espacio y de sus significados, sino todo lo contrario, ya que se asocia siempre a ámbitos concretos (cementerios, monumentos conmemorativos, etc.). Espacio e historia se combinan pues indefectiblemente en el concepto de conmemoración ${ }^{17}$, pero no son abundantes los marcos teóricos y los métodos para la correcta identificación y valoración patrimonial de estos lugares y, menos aún, para su activación como recurso social, turístico, urbanístico, paisajístico, etc. ${ }^{18}$.

\section{El patrimonio: un concepto polisémico, complejo y cambiante}

El concepto de patrimonio tiene un origen institucional y normativo ${ }^{19}$. Nace de la asignación de valores trascendentes a objetos, lugares, pautas o ideas, y expresa la necesidad del género humano de autoafirmarse en su tiempo y espacio; lo que cambia es la forma y significado con que se asignan estos valores. La cultura occidental encauzó el concepto hacia lo material y erudito desde el siglo xix y lo mantuvo y expandió globalmente hasta bien entrado el siglo xx. Se trata de la clásica construcción del valor patrimonial desde arriba (instituciones, leyes, literatura científica, etc.).

La traslación del objeto patrimonial al sujeto que lo crea y valora desde abajo (desde la base social; desde el territorio; desde lo local; desde colectivos concretos) es un proceso que, si bien con numerosos antecedentes, se acelera durante la segunda mitad del siglo pasado de la mano de las corrientes postmodernas y se consolida durante los primeros decenios del $\mathrm{XXI}^{20}$. Esto fuerza a un nuevo paradigma patrimonial en el que lo inmaterial, perceptivo y subjetivo ganan espacio frente a la citada consideración tradicional decimonónica que atribuía el protagonismo a lo material e inmueble (monumental y arqueológico, primero, y centros históricos, después). En la sociedad global, el patrimonio se apoya en conceptos generosos, elásticos, adaptativos, fluidos y a veces caprichosos que, aun con lagunas de concreción, facilitan una lectura nueva y un concepto patrimonial, cambiante y siempre provisional ${ }^{21}$. El patrimonio se convierte, despegado de la materialidad pero no del espacio, en un valor presente y siempre sometido al cambio social. Este valor se asocia a determinados elementos presentes en los territorios, o en la mente de sus moradores, y se legitima, desde arriba, por las instituciones públicas (académicas y normativas, fundamentalmente), o por la base social, desde abajo, como expresión de su identidad.

16 Foote y Azaryahu citados por García Álvarez 2009: 183.

17 Mitchell 2003.

18 Ortega 2005, Verdier 2010.

19 Silva Pérez 2016.

20 Castillo Ruiz 2007, Clark y Drury 2002.

21 Criado-Boado y Barreiro 2013, Silva Pérez y Fernández Salinas 2017. 
Se trata pues de un cambio importante y doble el que aporta la visión inmaterial del patrimonio: a) la protección se ha hecho más compleja y variada en razón de que lo que hay que proteger también lo es; y b) el sesgo de la Convención para la Salvaguardia del Patrimonio Inmaterial de la Unesco ${ }^{22}$ desplaza el interés desde la protección genérica a la salvaguardia; o, en términos de la propia convención, de la conservación a la viabilidad, asumida esta como un vasto campo de actuaciones que, sin una delimitación conceptual clara, van desde la identificación a la revitalización del patrimonio y que suponen todo un elenco de estrategias que aseguran la proyección del patrimonio inmaterial hacia el futuro.

\section{El marco normativo español sobre la memoria histórica España y su compleja relación con la memoria del período que media entre la II República y la Transición}

España es un país en el que las cuestiones de la memoria histórica suscitan una gran discusión y no pocas disensiones. Los escenarios de las batallas de Almansa o de Bailén no crean controversia social, pero no puede decirse lo mismo de la memoria de la Guerra Civil o del franquismo. La memoria histórica como reivindicación política se asienta en España durante el período de la Transición ${ }^{23}$, ya que la forma en que esta se realizó, poco exigente respecto al resarcimiento de las víctimas franquistas, sobre todo tras la promulgación de la Ley 46/1977 de Amnistía, generó una tardía aunque potente reacción que intenta establecer una lectura distinta del siglo xx en España y el reconocimiento y reparación de las víctimas de la Dictadura y de sus familiares ${ }^{24}$. Se trata de una tarea compleja en tanto que una parte de la sociedad española prefiere no revisar ese pasado con el pretexto de no trastocar las bases sobre las que se realizó la frágil y amenazada transición a la democracia ${ }^{25}$.

El interés por la memoria histórica se inicia en numerosas comunidades autónomas; Andalucía, Asturias, Cataluña, etc. En casi todas, esta atención se concreta en disposiciones normativas de distinto alcance ya en el siglo $\mathrm{XXI}^{26}$. Con carácter general para el conjunto del país, se promulga la Ley 52/2007 por la que se Reconocen y Amplían Derechos y se Establecen Medidas a Favor de Quienes Padecieron Persecución o Violencia durante la Guerra Civil y la Dictadura (más conocida como ley de la memoria histórica). Durante esos años se incrementan notablemente las asociaciones que reclaman el desagravio de las víctimas, así como las iniciativas de sindicatos y ayuntamientos, además de particulares, que impulsan acciones concretas, sobre todo la exhumación de familiares enterrados en fosas comunes o en cunetas de carreteras. Con ello surge el interés por identificar los lugares en los que se basa la recuperación de esa memoria (muros, prisiones, campos de concentración) y, en general, la interpretación espacial de los acontecimientos a ella ligados.

22 Unesco 2003.

23 Gil Gil 2009.

24 Ruiz Torres 2007.

25 Sección Española de Amnistía Internacional 2005.

26 Cuesta y Odriozola 2018. 


\section{La historia como objeto de protección patrimonial en España}

No es objeto de este artículo adentrarse en la red normativa que existe en España respecto al patrimonio. Baste señalar que, dado que la cultura es una competencia transferida a las comunidades autónomas, existen diecisiete leyes sobre patrimonio. No obstante, la Ley de Patrimonio Histórico Español 16/1985 sigue vigente en la escala estatal después de 34 años a pesar de algunos intentos de modernización y de su evidente desfase conceptual. El sesgo de esta ley se orienta a la mirada tradicional del patrimonio (mueble / inmueble, material / inmaterial), con un predominio del patrimonio monumental y urbano. El texto está más adaptado al entendimiento, y por ende reconocimiento, de la historia del arte, de la arquitectura, de la arqueología, etcétera, que a la de los hechos históricos propiamente dichos. Estos tienen poca cabida y desarrollo en ella pese a la existencia de los sitios históricos como tipo de bien de interés cultural inmueble. Su número es escaso (485, un 2,78 \% del total de bienes de interés cultural inmueble ${ }^{27}$ ) y no siempre aplicable a las consideraciones realizadas sobre la memoria histórica y los lugares sobre los que se proyecta. Además, su carácter es heterogéneo y heterodoxo; en ellos aparecen lugares como Vivar del Cid en las cercanías de Burgos (vinculado al supuesto lugar de nacimiento de Rodrigo Díaz); el cortijo del Fraile en Níjar (inspirador de la obra Bodas de Sangre de Federico García Lorca) o el acueducto de San Telmo (obra hidráulica para abastecer de agua a Málaga). Las vinculaciones de esta tipología normativa con la memoria histórica se producen de forma aleatoria y sin que haya existido, ni una reflexión teórica o técnica, ni un debate social sobre la manera en que dos realidades con bases comunes, los sitios históricos de las leyes de patrimonio y los lugares de la memoria histórica, debieran converger en un campo de registro y tutela común.

\section{El reconocimiento de la memoria histórica y de sus lugares en Anda- lucía}

\section{Contexto normativo y otros antecedentes}

En Andalucía, si bien la legitimación de la memoria histórica ha sido temprano, también ha sido lento y asimétrico. Al igual que en otras comunidades españolas, el desarrollo de varias iniciativas (bien desde lo público, bien desde la sociedad civil) ha dado lugar a un contexto social mucho más sensible a la memoria histórica ya bien entrado el siglo xxI. En este proceso, la identificación de una serie de Lugares de Memoria Histórica, primero, y de Memoria Democrática, después (ver sus diferencias más adelante) ha generado una lectura nueva de estos espacios y de sus significados, tanto desde el punto de vista histórico como del patrimonial. El devenir del proceso es corto, pero complejo (ver síntesis en la Tabla 2).

27 Ministerio de Educación, Cultura y Deporte 2017. 
Tabla 2. Contexto legal sobre memoria histórica en Andalucía

\begin{tabular}{|c|c|}
\hline Texto legal & Objeto \\
\hline Decreto $1 / 2001$ & $\begin{array}{l}\text { Indemnizaciones a expresos y represaliados con privación de libertad } \\
\text { durante más de tres anos }\end{array}$ \\
\hline Decreto $333 / 2003$ & $\begin{array}{l}\text { Indemnizaciones a expresos y represaliados con privación de libertad entre } \\
\text { tres meses y tres años }\end{array}$ \\
\hline Decreto 334/2003 & $\begin{array}{l}\text { Coordinación de actuaciones en torno a la memoria histórica y el } \\
\text { reconocimiento institucional y social de las personas desaparecidas durante } \\
\text { la Guerra Civil y la postguerra }\end{array}$ \\
\hline Decreto $521 / 2004$ & $\begin{array}{l}\text { Creación de la Comisión Interdepartamental para el Reconocimiento de las } \\
\text { Víctimas de la Guerra Civil y del Franquismo }\end{array}$ \\
\hline Decreto 54/2005 & Creación del Comisario para la Recuperación de la Memoria Histórica \\
\hline $\begin{array}{l}\text { Ley Orgánica } \\
2 / 2007\end{array}$ & $\begin{array}{l}\text { El Estatuto de Autonomía, que sustituye al inicial de 1981, recoge medidas } \\
\text { relativas a la memoria histórica }\end{array}$ \\
\hline Decreto $372 / 2010$ & $\begin{array}{l}\text { Indemnizaciones a mujeres que sufrieron formas de represión de la } \\
\text { dictadura franquista sobre su honor, intimidad y propia imagen }\end{array}$ \\
\hline Decreto $264 / 2011$ & $\begin{array}{l}\text { Creación y regulación de los Lugares de Memoria Histórica de Andalucía y } \\
\text { su catálogo }\end{array}$ \\
\hline Ley $2 / 2017$ & $\begin{array}{l}\text { Memoria Histórica y Democrática de Andalucía. Incorpora como nueva } \\
\text { figura los Lugares de Memoria Democrática de Andalucía y su catálogo }\end{array}$ \\
\hline Decreto $93 / 2018$ & $\begin{array}{l}\text { Creación y regulación del Consejo de la Memoria Histórica y Democrática } \\
\text { de Andalucía }\end{array}$ \\
\hline
\end{tabular}

Fuente: Los autores.

Los primeros textos legales relacionados con la memoria histórica tienen que ver con medidas para resarcir a afectados y familiares represaliados durante el franquismo y postfranquismo y la creación de órganos para la gestión de las actuaciones. El Estatuto de Autonomía para Andalucía de 2007 recoge esta sensibilidad y establece entre sus objetivos que los «poderes públicos velarán por la salvaguarda, conocimiento y difusión de la historia de la lucha del pueblo andaluz por sus derechos y libertades» ${ }^{28}$.

Tras otro decreto intermedio sobre indemnizaciones, se promulga el Decreto 264/201 1 por el que se crean y regulan los Lugares de Memoria Histórica de Andalucía y su correspondiente catálogo. Con esta medida legal, espacio y conmemoración se unen convocados por la memoria histórica toda vez que estos lugares consagran la ubicación de los hechos referidos como el sitio en el que historia, símbolo, reconocimiento, reparación y mensaje se conjugan y registran. Sin embargo, es importante tener presente que la declaración de Lugar de Memoria Histórica no significaba aún protección alguna del sitio. Para esto es necesario esperar seis años a la promulgación de la Ley de Memoria Histórica y Democrática 2/2017, aparecida diez años después de la ley española sobre la materia (ver más adelante). La ley andaluza supone un cambio notable en el reconocimiento de esta memoria, que ahora añade el sustantivo de democrática al de histórica, añadido que no está exento de cierta confusión

28 Art. $10 .^{\circ}$, punto $24 .^{\circ}$ del Estatuto para Andalucía de 2007. 
en las definiciones que maneja, y que se acentúa al establecer dos ámbitos cronológicos de aplicación que afectan a la determinación de las víctimas. Así, por Memoria Democrática se entiende: "La salvaguarda, conocimiento y difusión de la historia de la lucha del pueblo andaluz por sus derechos y libertades para hacer efectivo el ejercicio del derecho individual y colectivo a conocer la verdad de lo acaecido en la lucha por los derechos y libertades democráticas en el período que abarca desde la proclamación de la Segunda Republica española, el 14 de abril de 1931, hasta la entrada en vigor del Estatuto de Autonomía de Andalucía, el 11 de enero de 1982, así como la promoción del derecho a una justicia efectiva y a la reparación para las víctimas andaluzas del golpe militar y la Dictadura franquista $»^{29} y$ de sus familiares. De esta manera, por mor de coordinarse con las actuaciones vinculadas a la ley estatal 52/2007 en esta materia, quedan al margen de la consideración de víctimas aquellas del período republicano anterior al levantamiento de Franco y de la Transición, etapas que a otros efectos de la ley sí están plenamente concernidas.

Se afirma en la definición de estas víctimas que se actúa de conformidad con la Resolución 60/147 de las Naciones Unidas ${ }^{30}$; pero en ese texto internacional no se definen las víctimas en términos de lucha por derechos, acción que también estaría incluida, sino que, de forma genérica, se tiene por tales «... a toda persona que haya sufrido daños, individual o colectivamente, $[\ldots]$ como consecuencia de acciones $\mathrm{u}$ omisiones que constituyan una violación manifiesta de las normas internacionales de derechos humanos o una violación grave del derecho internacional humanitario $»^{31}$. En consecuencia, no parece tan claro que la ley andaluza incorpore a personas que, sin un planteamiento proactivo en tal lucha, también fueran objeto de represión en Andalucía durante aquel período (por ejemplo, personas que sin filiación política fueron acusadas dolosamente de pertenencia a partidos o grupos de izquierdas) y, mucho menos, a las personas que perteneciendo a sectores conservadores fueron también injustamente objeto de represión a causa de sus ideas en las zonas de Andalucía que permanecieron más tiempo fieles al gobierno republicano. En este sentido, hay que recordar que la ley estatal de Memoria Histórica 52/2007 establece que sus objetivos son: «reconocer y ampliar derechos a favor de quienes padecieron persecución o violencia, por razones políticas, ideológicas, o de creencia religiosa, durante la Guerra Civil y la Dictadura, promover su reparación moral y la recuperación de su memoria personal y familiar, y adoptar medidas complementarias... $»^{32}$. No es condición sine qua non para ella haber formado parte de la lucha por los derechos para obtener su reconocimiento y acogerse a los derechos que determina.

Otra duda es el hecho de que se identifique a las víctimas exclusivamente con andaluzas y andaluces. En este sentido, podría pensarse que, como señala el Estatu-

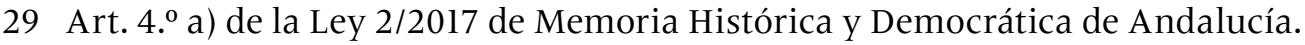

30 Ibidem, Art. $\left.4 .^{\circ} \mathrm{b}\right)$

31 Parágrafo 8 de la Resolución 60/147 de las Naciones Unidas.

32 Art. $1 .^{\circ}$, punto $1 .^{\circ}$ de la Ley 52/2007 de por la que se Reconocen y Amplían Derechos y se Establecen Medidas en Favor de Quienes Padecieron Persecución o Violencia durante la Guerra Civil y la Dictadura. 
to de Autonomía de Andalucía de 2007, «gozan de la condición política de andaluces o andaluzas los ciudadanos españoles que, de acuerdo con las leyes generales del Estado, tengan vecindad administrativa en cualquiera de los municipios de Andalucía» ${ }^{33}$. Pero, aunque no parece que sea el espíritu de la ley, quedarían excluidos aquellos españoles que estuviesen en Andalucía de tránsito cuando aconteció la conculcación de sus derechos (circunstancia que fue frecuente durante el período bélico y postbélico) y todos los extranjeros, estuviesen de tránsito o residiendo en Andalucía, durante el período considerado por la ley. En todo caso, el número de víctimas estimadas por las autoridades públicas andaluzas alcanza las $45.776^{34}$

Un aspecto complejo de analizar es el de las inversiones, realizadas o previstas, en el relación con la política de memoria histórica en Andalucía; especialmente en un período de cambios políticos como el iniciado a finales de 2018. Existe información sobre los presupuestos consignados para el desarrollo de la ley (Tabla 3), pero, además de tratarse de partidas con un incremento cada vez menor, en la práctica su desarrollo efectivo en los presupuestos anuales está muy comprometido. Como ejemplo, baste señalar que la cifra consignada prevista para 2020 (2.295.000 €) se concretó en los presupuestos para ese ejercicio económico de la Junta con una rebaja superior al $30 \%\left(1.597 .354 €^{35}\right)$, y esto antes de la revisión obligada de los presupuestos impuesta por la negación del Gobierno central para que la Junta de Andalucía acuda a los mercados externos para financiarse. Hecho que puede repercutir en un nuevo recorte de esa partida.

Tabla 3. La Memoria Histórica y Democrática en sus presupuestos

\begin{tabular}{lrr}
\hline Año & Presupuesto & Incremento \\
\hline 2017 & 1.313 .426 & - \\
2018 & 1.724 .752 & 31,13 \\
2019 & 2.055 .000 & 19,15 \\
2020 & 2.295 .000 & 11,68 \\
2021 & 2.511 .000 & 9,41 \\
2022 & 2.631 .000 & 4,79 \\
\hline
\end{tabular}

Fuente: Informe de seguimiento de las actuaciones en materia de Memoria Democrática 2017-2018

El hecho que hace más innovador al texto legal es que la memoria histórica es asumida como legado cultural. Esta circunstancia, que patrimonializa la memoria, se verá reforzada por la transformación del citado Catálogo de Lugares de la Memoria Histórica de Andalucía del Decreto 264/201 l en el Inventario de los Lugares de Memoria Democrática de Andalucía que, más allá de la nomenclatura, será trascendental en ese proceso de patrimonialización dado que la ley señala que dicho inven-

33 Art. $5 .^{\circ}$, punto $1 .^{\circ}$ del Estatuto de Autonomía de Andalucía.

34 Consejería de la Presidencia, Administración Local y Memoria Democrática, 2018, p. 15.

35 Proyecto de Ley del Presupuesto de la Comunidad Autónoma de Andalucía 2020. 
tario se integrará a su vez en otro: el Inventario General de Bienes Reconocidos del Patrimonio Histórico Andaluz, que, como su nombre indica, ya forma parte de manera oficial del legado cultural reconocido de la comunidad autónoma (Figura 1 ). No obstante, este inventario tiene un carácter secundario y su tutela recae menos en la administración cultural y más en otras políticas sectoriales (fundamentalmente la ordenación del territorio y el medio ambiente) y locales (urbanismo). Además, este segundo inventario aún no ha sido implementado doce años después de promulgada la ley y cuando ya existe un borrador de una nueva.

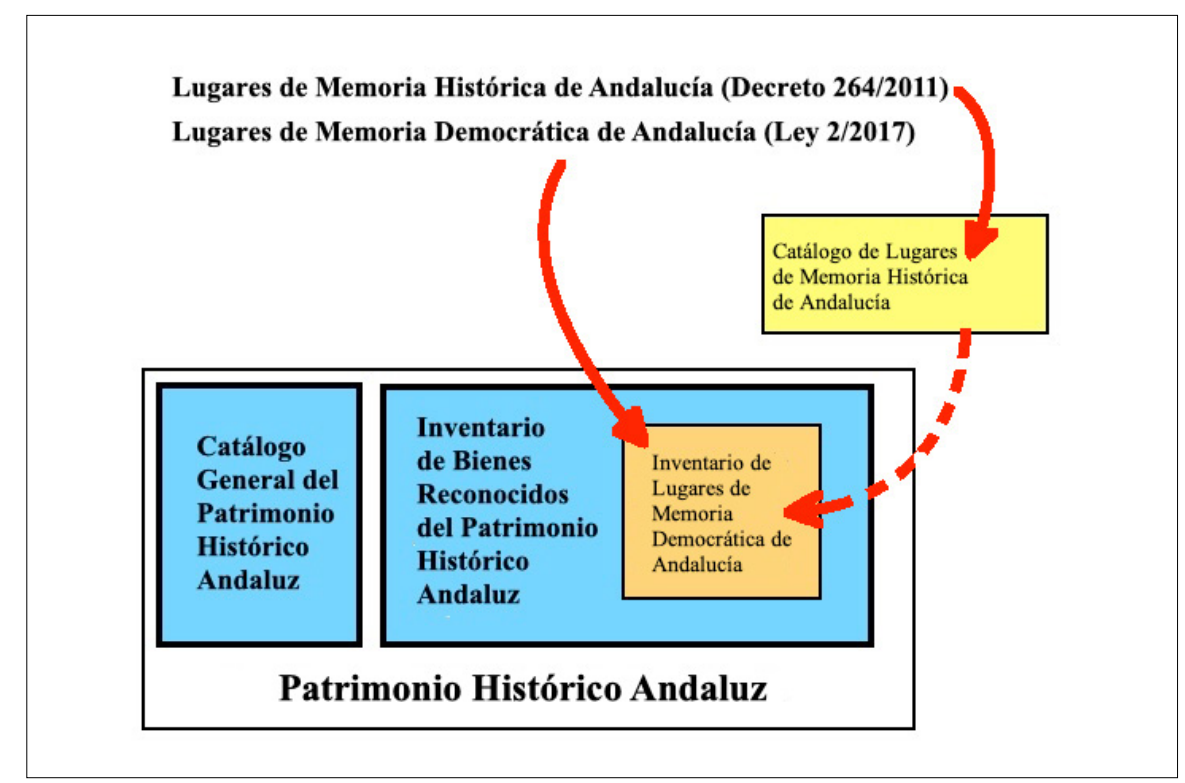

Figura 1. Los Lugares de Memoria Histórica y Democrática y su encaje patrimonial

Fuente: Elaboración propia

Para completar estos antecedentes, hay que señalar que, por el Decreto 93/2018, se crea el Consejo de la Memoria Histórica y Democrática de Andalucía, con amplias competencias en cuanto a elaborar informes y, en lo relativo a este artículo, a emitir opinión sobre las solicitudes de incoación de inscripción en el Inventario de Lugares de Memoria Democrática de Andalucía. Ya en 2019, tras las elecciones de finales del año anterior y el cambio de color político del gobierno andaluz, todo el compendio legal-administrativo descrito ha pasado del entorno de la Consejería de Presidencia de la Junta de Andalucía al de la de Cultura y Patrimonio Histórico. Esto significa un avance en la patrimonialización de esta memoria, pero se lleva a cabo en medio de la incertidumbre sobre el apoyo político que la Memoria Democrática reciba durante los próximos años; especialmente por la dependencia del gobierno andaluz, formado por una coalición del Partido Popular y Ciudadanos, para desarrollar su política del partido de ultraderecha Vox, que puso como condición de pacto de gobierno que se derogase la ley de 2017 a lo largo de la legislatura y que, además, preside actualmente la Comisión de Cultura del Parlamento de Andalucía, con competencias directas sobre la Memoria Democrática. 


\section{La dimensión espacial y temporal de la memoria histórica en Andalucía}

A efectos de este trabajo interesa conocer el qué (los lugares de memoria y su tipificación); el quién (los agentes que promueven su reconocimiento); el dónde (carácter y expresión geográfica de los lugares) y el cuándo (período en el que se produce el hecho que conmemoran: Guerra Civil, Dictadura o Transición).

\section{Los Lugares de Memoria Histórica de Andalucía}

Como ya ha sido citado, estos lugares emanan de lo dispuesto en el Decreto 264/201 1 , que los crea y regula, así como su catálogo. Se trata de una iniciativa institucional, si bien reclamada por los colectivos regionales y locales de la memoria histórica en la comunidad autónoma. Aunque las declaraciones no impliquen ningún nivel de protección, el texto está cargado de una patente vocación e intención tutelar ya que el decreto tiene "por objeto incitar a las Administraciones Públicas andaluzas a inventariar, preservar y promover esos sitios y lugares de memoria» ${ }^{36}$. Para su identificación se prescribe «la elaboración de un informe [...] que incluya, además de la información sobre la ubicación del Lugar, toda la información histórica sobre los hechos y acontecimientos ocurridos en el mismo ${ }^{37}$ durante la Guerra Civil y el franquismo. La declaración de los cincuenta lugares que componen el catálogo se ha realizado entre 2011 y 2013 (Tabla 4).

Los tipos de Lugares de Memoria Histórica de Andalucía más frecuentes son las fosas (17), seguida de construcciones connotadas (12) y, ya a una cierta distancia, de zonas (7). Estos tres tipos suman 36 de los 50 Lugares declarados. En lo que atañe a su identificación espacial, no ofrecen en ningún caso una descripción pormenorizada de su ubicación, extensión y otros aspectos de interés geográfico. Así, la ruta del barranco de la Huesa de Villaviciosa, pese a su nombre, es más bien una zona: Villaviciosa y la sierra de su término municipal. Otros lugares son bastante imprecisos, como es el caso del cerco de Granada, o generan dudas sobre el ámbito al que se refieren: el refugio antiaéreo de Jaén, por ejemplo, alude a seis refugios y, entre ellos, destaca los de la plaza de Santiago o el del antiguo hospital de San Juan de Dios, sin que pueda saberse con certeza si son seis, dos o uno los refugios reconocidos. La declaración más equívoca es la de la carretera entre Málaga y Almería: «... quedan partes a lo largo del trayecto que merecen ser recordadas en memoria del drama sufrido por la población civil» en la desbandada de Málaga ${ }^{38}$. Aunque en el texto se hace referencia a localidades, sobre todo en la provincia de Málaga (El Rincón de la Victoria, Torre del Mar, etc.) y en la de Granada (La Herradura, Almuñécar, etc.), se desconoce hasta qué lugar alcanza de esta provincia. Además, al año siguiente de haber sido declarado este lugar, se designa Lugar de Memoria Histórica la carretera

36 Texto introductorio del Decreto 264/2011 sobre los Lugares de Memoria Histórica de Andalucía

37 Art. $2 .^{\circ}$, punto $6 .^{\circ}$, ibidem.

38 Acuerdo de 20 de marzo de 2012 del Consejo de Gobierno por el que se Declaran Catorce Lugares de Memoria Histórica de Andalucía, Capítulo ii. 
de Málaga a Almería en la desembocadura del río Guadalfeo en Salobreña que, al menos en teoría, ya formaba parte de la declaración anterior.

Tabla 4. Lugares de Memoria Histórica de Andalucía (Decreto 264/2011)

\begin{tabular}{|c|c|c|c|c|c|}
\hline $\begin{array}{l}\text { Lugar (municipio, } \\
\text { provincia) }\end{array}$ & $\stackrel{\circ}{\varrho}$ & 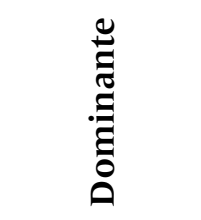 & 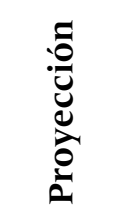 & 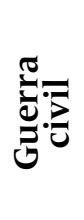 & 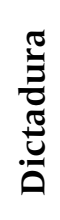 \\
\hline $\begin{array}{l}\text { Parque de las Almadrabillas } \\
\text { (Almería) }\end{array}$ & Memorial & Urbana & Punto & & $X$ \\
\hline $\begin{array}{l}\text { Portada de la Cárcel del } \\
\text { Ingenio (Almería) }\end{array}$ & Construcción & Urbana & Punto & $\mathrm{X}$ & $X$ \\
\hline Refugios antiaéreos (Almería) & Construcción & Urbana & Punto & $\mathrm{X}$ & \\
\hline $\begin{array}{l}\text { Castillo de San Sebastián } \\
\text { (Cádiz) }\end{array}$ & Construcción & Urbana & Punto & $X$ & \\
\hline $\begin{array}{l}\text { Muros de Puerta de Tierra } \\
\text { (Cádiz) }\end{array}$ & Muro & Urbana & Punto & $X$ & \\
\hline $\begin{array}{l}\text { Fosa de las Mujeres } \\
\text { (Grazalema, Cảdiz) }\end{array}$ & Fosa & Rural & Punto & $\mathrm{X}$ & \\
\hline $\begin{array}{l}\text { Fosa cortijo El Marrufo (Jerez } \\
\text { de la Front., Cádiz) }\end{array}$ & Fosa & Rural & Punto & $\mathrm{X}$ & \\
\hline $\begin{array}{l}\text { La Sauceda (Jerez Fr., Cádiz, y } \\
\text { Cortes Fr., Málaga) }\end{array}$ & Zona & Rural & Área & $X$ & \\
\hline $\begin{array}{l}\text { Penal (El Puerto de Santa } \\
\text { María, Cádiz) }\end{array}$ & Construcción & Urbana & Punto & $X$ & $X$ \\
\hline $\begin{array}{l}\text { Muros cementerios de La } \\
\text { Salud y S. Rafael (Córd.) }\end{array}$ & Muro & Urbana & Punto & $X$ & \\
\hline $\begin{array}{l}\text { Ruta guerrillera de Los Juiles } \\
\text { (Montoro, Córdoba) }\end{array}$ & Ruta & Rural & Línea & & $X$ \\
\hline $\begin{array}{l}\text { Fosa Cementerio La } \\
\text { Guijarrosa (Santaella, Córdo.) }\end{array}$ & Fosa & Urbana & Punto & $\mathrm{X}$ & \\
\hline $\begin{array}{l}\text { Fosa del Cementerio } \\
\text { (Santaella, Córdoba) }\end{array}$ & Fosa & Urbana & Punto & $X$ & \\
\hline $\begin{array}{l}\text { Batalla de Valsequillo } \\
\text { (Valsequillo, Córdoba) }\end{array}$ & Zona & Rural & Área & $X$ & \\
\hline $\begin{array}{l}\text { Ruta barranco La Huesa } \\
\text { (Villaviciosa, Córdoba) }\end{array}$ & Ruta & Rural & Línea & & $X$ \\
\hline $\begin{array}{l}\text { Carretera (Alfacar y Víznar, } \\
\text { Granada) }\end{array}$ & Ruta & Rural & Línea & $X$ & \\
\hline $\begin{array}{l}\text { Tapia del Cementerio de San } \\
\text { José (Granada) }\end{array}$ & Muro & Urbana & Punto & $X$ & \\
\hline $\begin{array}{l}\text { Puerta de la antigua Prisión } \\
\text { Provincial (Granada) }\end{array}$ & Construcción & Urbana & Punto & $X$ & $X$ \\
\hline $\begin{array}{l}\text { Cerco y estructuras } \\
\text { defensivas (Granada) }\end{array}$ & Zona & Periurbano & Área & $X$ & \\
\hline $\begin{array}{l}\text { Barranco de El Carrizal de } \\
\text { Órgiva (Granada) }\end{array}$ & Zona & Rural & Área & $X$ & \\
\hline
\end{tabular}




\begin{tabular}{|c|c|c|c|c|c|c|}
\hline $\begin{array}{l}\text { Lugar (municipio, } \\
\text { provincia) }\end{array}$ & $\stackrel{̊}{\mathscr{F}}$ & $\begin{array}{l}\stackrel{\Xi}{\Xi} \\
\stackrel{\Xi}{\Xi} \\
\stackrel{\Xi}{\Xi}\end{array}$ & 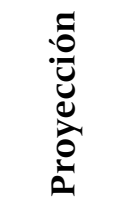 & 苞 & 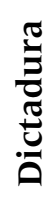 & 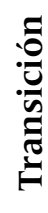 \\
\hline $\begin{array}{l}\text { Ctra. Málaga-Alm., Guadalfeo } \\
\text { (Salobreña, Grana.) }\end{array}$ & Lugar & Rural & Punto & $X$ & & \\
\hline $\begin{array}{l}\text { Fosa del Cementerio Viejo } \\
\text { (Almonte, Huelva) }\end{array}$ & Fosa & Urbana & Punto & $\mathrm{X}$ & & \\
\hline $\begin{array}{l}\text { Antigua Prisión Provincial } \\
\text { (Huelva) }\end{array}$ & Construcción & Urbana & Punto & $\mathrm{X}$ & $\mathrm{X}$ & $\mathrm{X}$ \\
\hline $\begin{array}{l}\text { Muro del Parque Moret } \\
\text { (Huelva) }\end{array}$ & Muro & Urbana & Punto & $\mathrm{X}$ & & \\
\hline Isla de Saltés (Huelva) & Zona & Rural & Punto & $\mathrm{X}$ & $X$ & \\
\hline $\begin{array}{l}\text { Fosa común del Cementerio } \\
\text { (Nerva, Huelva) }\end{array}$ & Fosa & Urbana & Punto & $\mathrm{X}$ & & \\
\hline $\begin{array}{l}\text { Fosa común (La Palma del } \\
\text { Condado, Huelva) }\end{array}$ & Fosa & Urbana & Punto & $\mathrm{X}$ & & \\
\hline $\begin{array}{l}\text { El Membrillo Bajo (Zalamea } \\
\text { la Real, Huelva) }\end{array}$ & Zona & Rural & Punto & $\mathrm{X}$ & & \\
\hline $\begin{array}{l}\text { Fosas del Cementerio } \\
\text { (Andújar, Jaén) }\end{array}$ & Fosa & Urbana & Punto & & $\mathrm{X}$ & \\
\hline Refugio antiaéreo (Jaén) & Construcción & Urbana & Punto & $\mathrm{X}$ & & \\
\hline $\begin{array}{l}\text { Fosa común del Cementerio } \\
\text { (Linares, Jaén) }\end{array}$ & Fosa & Urbana & Punto & & $\mathrm{X}$ & \\
\hline $\begin{array}{l}\text { Vestigios de batalla (Lopera, } \\
\text { Jaén) }\end{array}$ & Zona & Periur. & Área & $\mathrm{X}$ & & \\
\hline $\begin{array}{l}\text { Fosas del Cementerio } \\
\text { (Martos, Jaén) }\end{array}$ & Fosa & Urbana & Punto & & $\mathrm{X}$ & \\
\hline $\begin{array}{l}\text { Fosa común del Cementerio } \\
\text { (Úbeda, Jaén) }\end{array}$ & Fosa & Urbana & Punto & & $\mathrm{X}$ & \\
\hline $\begin{array}{l}\text { Fosa del Cement. Vva.de } \\
\text { Cauche (Antequera, Má.) }\end{array}$ & Fosa & Urbana & Punto & $\mathrm{X}$ & & \\
\hline $\begin{array}{l}\text { Fosa común de (Istán, } \\
\text { Málaga) }\end{array}$ & Fosa & Urbana & Punto & $\mathrm{X}$ & & \\
\hline $\begin{array}{l}\text { Fosa en el cementerio de San } \\
\text { Rafael (Málaga) }\end{array}$ & Fosa & Urbana & Punto & $\mathrm{X}$ & & \\
\hline $\begin{array}{l}\text { Antigua Prisión Provincial } \\
\text { (Málaga) }\end{array}$ & Construcción & Urbana & Punto & $\mathrm{X}$ & $X$ & \\
\hline $\begin{array}{l}\text { Antigua Cárcel de Mujeres } \\
\text { (Málaga) }\end{array}$ & Construcción & Urbana & Punto & $\mathrm{X}$ & $\mathrm{X}$ & \\
\hline $\begin{array}{l}\text { Carretera Málaga-Almería } \\
\text { (Málaga-Granada) }^{2}\end{array}$ & Ruta & Rural & Línea & $\mathrm{X}$ & & \\
\hline $\begin{array}{l}\text { Cementerio de San Lorenzo } \\
\text { (Ronda, Málaga) }\end{array}$ & Fosa & Urbana & Punto & $\mathrm{X}$ & & \\
\hline $\begin{array}{l}\text { Fosa común del Cementerio } \\
\text { (Teba, Málaga) }\end{array}$ & Fosa & Urbana & Punto & $X$ & & \\
\hline
\end{tabular}




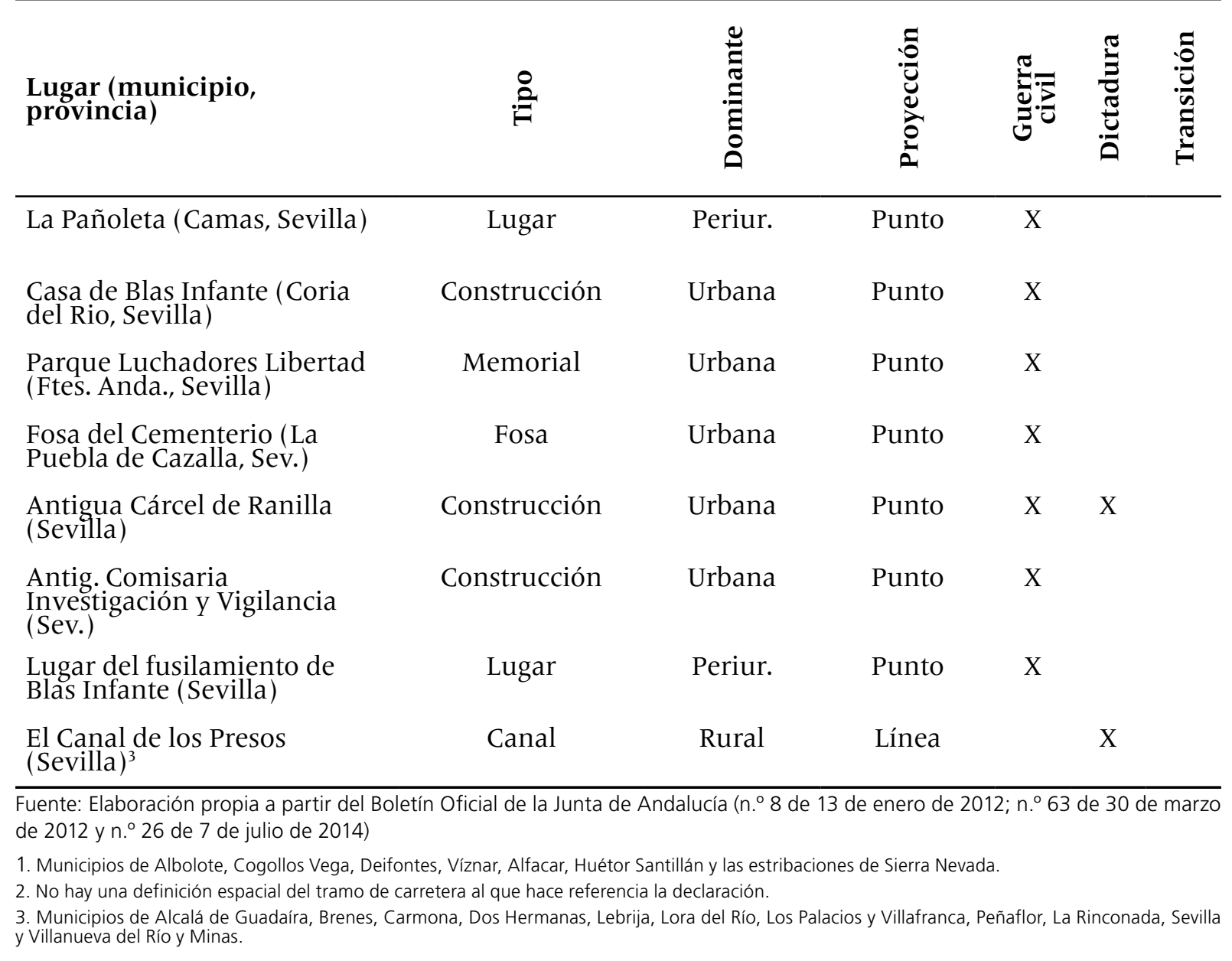

Otro caso confuso es el valle de la Sauceda de Cádiz y Málaga. En su descripción se señala que dentro de este espacio se halla el cortijo de El Marrufo, cuando la fosa de este cortijo ya había sido declarada Lugar de Memoria Histórica un año antes, sin que ahora se señale si la nueva inscripción es una ampliación de aquella o cómo ha de entenderse la yuxtaposición de ambos sitios. Esta imprecisión espacial afecta también a otros lugares, como los refugios antiaéreos de Almería o la ruta guerrillera de «Los Jubiles».

En cuanto a la distribución provincial (Figura 2), oscilan entre los seis y ocho Lugares por provincia (Málaga y Sevilla: ocho; Huelva: siete; Cádiz, Córdoba, Granada y Jaén: seis), salvo Almería, que tiene tres. En solo tres provincias (Huelva, Málaga y Sevilla) se concentra casi la mitad de los lugares declarados (23 de los 50).

Los Lugares de Memoria Histórica de Andalucía se localizan muy mayoritariamente en núcleos poblacionales y sus proximidades. De los 50, 37 son urbanos (33) o periurbanos (4). Solo 13 se dispersan por el espacio rural. Ninguno de ellos se localiza en espacios de dominante natural. Desde el punto de vista de su proyección o expresión cartográfica, se concretan muy mayoritariamente en puntos (40), frente a 5 que tienen carácter lineal (rutas, canal, etc.) y otros cinco referidos a áreas o zonas.

Con relación a los períodos en los que se desarrollan los hechos objeto de reconocimiento, la mayoría se corresponde específicamente con la Guerra Civil (34), 


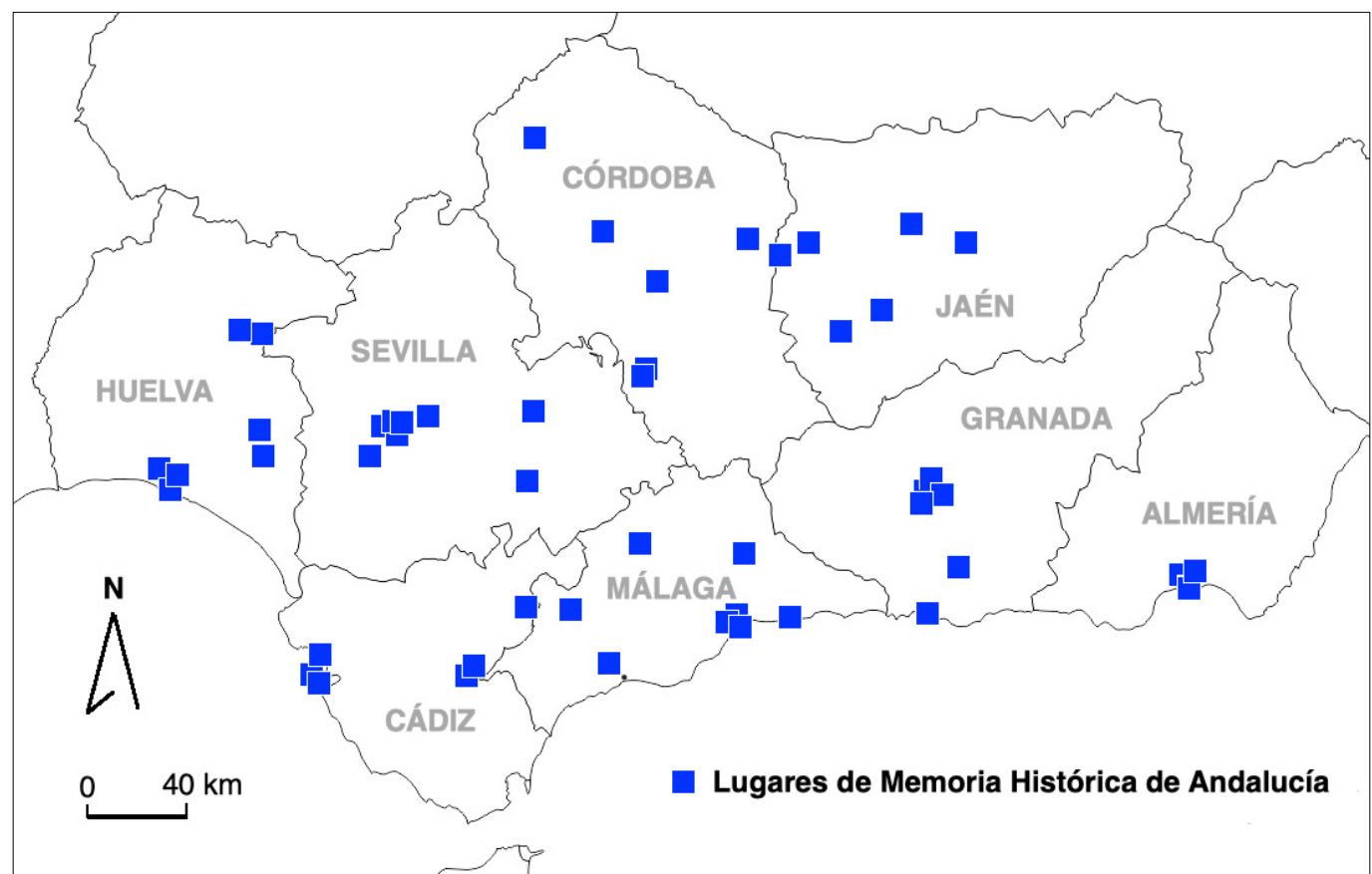

Figura 2. Distribución provincial de los Lugares de Memoria Histórica de Andalucía Fuente: Elaboración propia

aunque la casa de Blas Infante en Coria del Río fuese ideada y ocupada por este protagonista del andalucismo histórico durante la II República y apenas un par de semanas tras el golpe franquista. Hay ocho lugares de memoria histórica que abarcan, al menos, una parte del período bélico y, también, de la Dictadura, todos ellos prisiones, salvo el campo de concentración de la isla de Saltés (Huelva), que funcionó en los últimos tiempos de la guerra y que se desmanteló en el mismo 1939. Exclusivamente relativos al período de la Dictadura hay siete lugares relacionados, la mayoría perteneciente a la provincia de Jaén, dado que, al ser tomada en buena parte por las tropas franquistas al final de la guerra, sufrió la represión ya terminada la contienda. La antigua Prisión Provincial de Huelva es un caso especial, dado que en la determinación de sus valores se hace especial referencia a su condición de lugar de confinamiento de homosexuales (aspecto este que no sucedió solo en esta prisión ${ }^{39}$ ) y que alcanza hasta 1978, ya en el período de la Transición.

\section{Los Lugares de Memoria Democrática de Andalucía}

La Ley 2/2017 de la Memoria Democrática de Andalucía supera el concepto de Lugar de Memoria Histórica del Decreto 264/2011 y propone un nuevo tipo de declaración, Lugar de Memoria Democrática, y de registro, el Inventario de Lugares de Memoria Democrática de Andalucía. Estos espacios son, o bien Lugares de Memoria Democrática propiamente dichos ( [ámbito] que revele interés para la Comunidad Autónoma [...], por haberse desarrollado en él hechos de singular relevancia por su significación histórica, simbólica o por su repercusión en la memoria colectiva» $\left.{ }^{40}\right), 0$ bien los Senderos ( «conjunto formado por dos o más Lugares de Memoria Democrá39 Jurado Marín, 2014.

40 Art. $21 .^{\circ}$ de la Ley 2/2017 de la Memoria Democrática de Andalucía. 
tica de Andalucía que se encuentren uno a continuación de otro y tengan criterios interpretativos comunes de carácter histórico, paisajístico o simbólico, o valores relevantes de tipo ambiental, etnográfico o antropológico» $\left.{ }^{41}\right)$.

El texto legal dispone la aproximación a la Ley del Patrimonio Histórico Andaluz al considerar condición sine qua non para que un Lugar de Memoria Democrática sea declarado como tal que "revele interés [...] como patrimonio histórico»" ${ }^{42}$ ligado a la memoria del pueblo andaluz, tanto en relación con sus derechos y libertades, como con su padecimiento de represión y violencia.

Desde el punto de vista espacial, los Lugares de Memoria Democrática deben estar ubicados en Andalucía (lo que de otra forma habría creado conflictos jurisdiccionales con otras comunidades o países). La ley recoge tipologías concretas (espacios, inmuebles o parajes), aunque ello no signifique que en las declaraciones se especifique a qué tipología corresponde cada lugar. Por otro lado, prevé que los Lugares de Memoria Democrática se incluyan en el citado Inventario de Lugares de Memoria Democrática de Andalucía (Figura 1), que se plantea como una sección del también citado Inventario de Bienes Reconocidos del Patrimonio Histórico Andaluz establecido por la Ley 14/2007 del Patrimonio Histórico de Andalucía. Con ello se confirma el desplazamiento al ámbito administrativo patrimonial de estos lugares, ya que los procesos de tramitación de los expedientes para la inclusión en dicho inventario siguen un proceso similar al que se implementa en otras declaraciones patrimoniales. La forma con que se habían declarado los Lugares de Memoria Histórica del Decreto 264/2011 se considera insuficiente y, por ello, se necesita un protocolo más preciso desde el mismo momento de incoación de los expedientes que incluirá, como mínimo: a) la identificación del bien; b) su descripción; c) su delimitación cartográfica y coordenadas geográficas; y d) las medidas cautelares que fuesen necesarias para su protección $^{43}$.

El resto de los trámites también se asimila a la de los expedientes de declaraciones patrimoniales: suspensiones cautelares de obras; información pública y publicación en el Boletín Oficial de la Junta de Andalucía; sistemas de autorizaciones; obligaciones de los titulares; régimen de protección y conservación; etc. Respecto a la protección, y como ya ha sido mencionado, la ley transfiere la protección de los lugares de Memoria Democrática al planeamiento espacial (urbanístico y de ordenación territorial), así como a las políticas medioambientales.

La ley se encuentra con que ya existían los 50 Lugares de Memoria Histórica declarados en razón del Decreto 264/201 1 (Tabla 3) y prevé su conversión al formato de Lugares de Memoria Democrática. El Informe de la Consejería de la Presidencia, Administración Local y Memoria Democrática de 2019 señala que ya se están realizando los trámites administrativos al efecto. Al margen de esta reformulación de los Lugares de Memoria Histórica, en julio de 2017, pocos meses después de aprobada

41 Art. 22. ${ }^{\circ}$, pto. 1. ${ }^{\circ}$, ibidem.

42 Art. $21 .^{\circ}$, ibidem.

43 Art. $24 .^{\circ}$, punto $2 .^{\circ}$, ibidem. 
Tabla 5. Sitios valorados para su declaración como Lugares de Memoria Democrática de Andalucía el 18 de julio de 2017

\begin{tabular}{|c|c|c|c|c|c|c|c|}
\hline $\begin{array}{l}\text { Lugar (municipio, } \\
\text { provincia) }\end{array}$ & 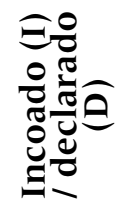 & $\stackrel{\circ}{:}$ & 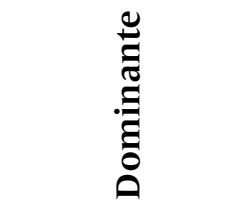 & 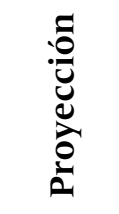 & 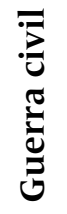 & 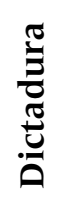 & 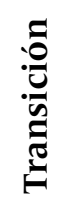 \\
\hline $\begin{array}{l}\text { Fortificación del Estrecho } \\
\text { de Gibraltar (Cád.) }\end{array}$ & - & Zona & Rural-Natural & Área & $\mathrm{X}$ & $\mathrm{X}$ & \\
\hline $\begin{array}{l}\text { Fosa Cementerio S. Roque, } \\
\text { Pto. Real (Cádiz) }\end{array}$ & $\mathrm{D}$ & Fosa & Urbano & Punto & $\mathrm{X}$ & & \\
\hline $\begin{array}{l}\text { Plaza de la Constitución de } \\
\text { Baena (Córdoba) }\end{array}$ & $\mathrm{D}$ & Lugar & Urbano & Punto & $\mathrm{X}$ & & \\
\hline $\begin{array}{l}\text { Fosa del cementerio de } \\
\text { Baena (Córdoba) }\end{array}$ & $\mathrm{D}$ & Fosa & Urbano & Punto & $\mathrm{X}$ & $\mathrm{X}$ & \\
\hline $\begin{array}{l}\text { Refugio antiaéreo, pl. } \\
\text { Espana, Vva. de Córdo. }\end{array}$ & I & Construc. & Urbano & Punto & $\mathrm{X}$ & & \\
\hline $\begin{array}{l}\text { Colonia de Víznar } \\
\text { (Granada) }\end{array}$ & I & Lugar & Periurbano & Punto & $\mathrm{X}$ & & \\
\hline $\begin{array}{l}\text { Convento de Santa Úrsula } \\
\text { de Jaén }\end{array}$ & I & Construc. & Urbano & Punto & & $\mathrm{X}$ & \\
\hline $\begin{array}{l}\text { Campo concentr. de Stgo. e } \\
\text { Higuera (Jaén) }\end{array}$ & I & Lugar & Periurbano & Punto & & $\mathrm{X}$ & \\
\hline $\begin{array}{l}\text { Cárcel vieja de Úbeda } \\
\text { (Jaén) }\end{array}$ & I & Construc. & Urbano & Punto & & $\mathrm{X}$ & \\
\hline $\begin{array}{l}\text { Esquina asesinato } \mathrm{M}^{\mathrm{el}} \mathrm{J} . \mathrm{G}^{\mathrm{a}} \\
\text { Caparrós, Málaga }\end{array}$ & $\mathrm{D}$ & Lugar & Urbano & Punto & & & $\mathrm{X}$ \\
\hline $\begin{array}{l}\text { Palacio de la Aduana de } \\
\text { Málaga }\end{array}$ & I & Construc. & Urbano & Punto & & $\mathrm{X}$ & \\
\hline $\begin{array}{l}\text { Jefatura Superior de } \\
\text { Policía Gavidia, Sevilla }\end{array}$ & I & Construc. & Urbano & Punto & & $\mathrm{X}$ & $\mathrm{X}$ \\
\hline $\begin{array}{l}\text { Capitanía General de la } \\
\text { Gavidia, Sevilla }\end{array}$ & I & Construc. & Urbano & Punto & $\mathrm{X}$ & & \\
\hline $\begin{array}{l}\text { Lugar asesinato Francisco } \\
\text { R. Ledesma, Sevill. }\end{array}$ & I & Lugar & Urbano & Punto & & & $\mathrm{X}$ \\
\hline
\end{tabular}

Fuente: Elaboración propia a partir de la Sesión de la Junta de Gobierno (Portal de la Junta de Andalucía https://www.juntadeandalucia.es/organismos/consejo/sesion/detalle/127824.html) y del Boletín Oficial de la Junta de Andalucía (n. ${ }^{\circ} 232$ de 4 de diciembre de 2017; n. ${ }^{\circ} 175$ de 10 de septiembre de 2018; n. ${ }^{\circ} 10$ de 16 de enero de 2019 y n. ${ }^{\circ} 11$ de 17 de enero de 2019 ).

la ley, ya se había concluido la fase de valoración previa de 14 Lugares de Memoria Democrática basada en los nuevos criterios (Tabla 5). En noviembre de ese mismo año se procede a la primera inscripción en el Inventario de Lugares de Memoria Democrática de Andalucía: la esquina del asesinato de Manuel José García Caparrós, que se había producido el 4 de diciembre de 1977 durante la celebración de la manifestación a favor de la autonomía de Andalucía y que ha de entenderse en la oportunidad de contar con tal inscripción de cara al cuadragésimo aniversario de aquel hecho (Figura 3). Desde el punto de vista espacial, las inscripciones no incor- 


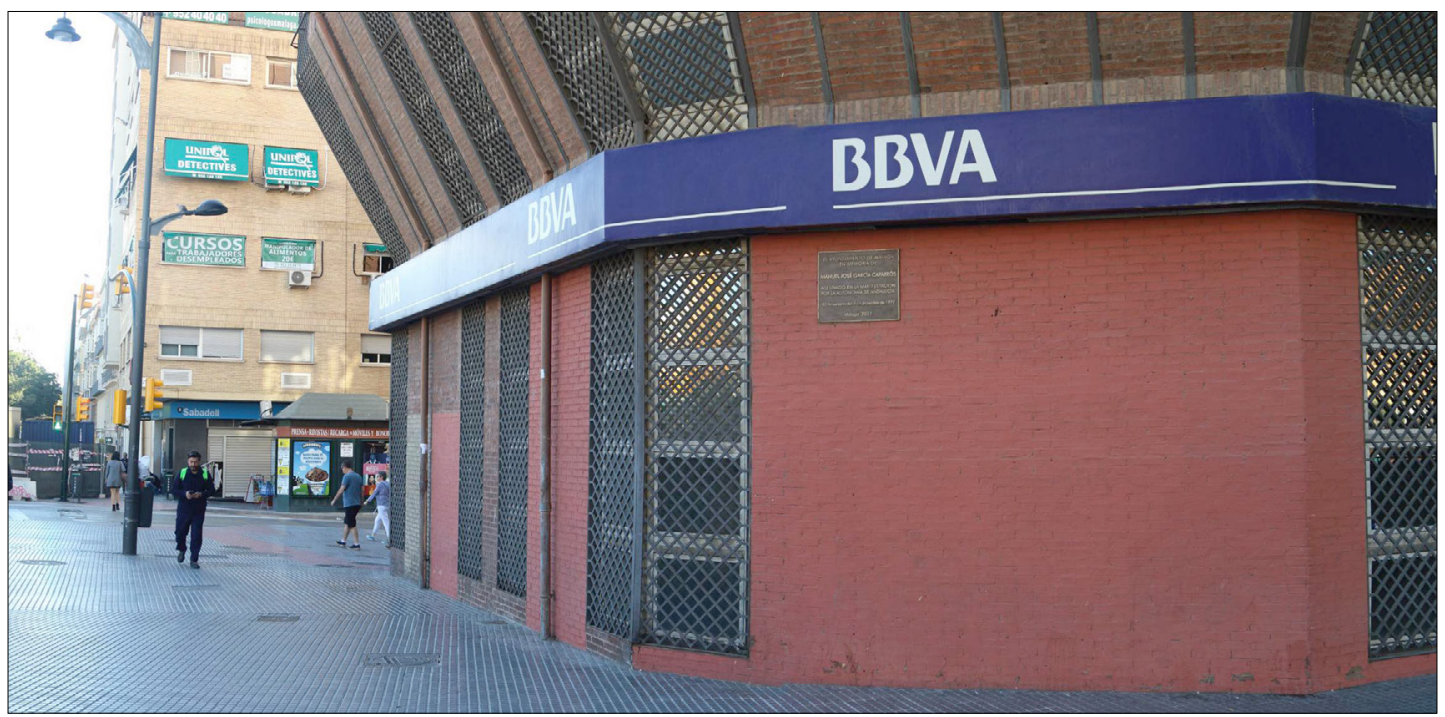

Figura 3. Lugar de Memoria Democrática de Andalucía en la esquina del asesinato de Manuel García Caparrós en Málaga el 4 de diciembre de 1977

Fuente: Archivo fotográfico de los autores (abril de 2019).

poran, como lo hacen las de los bienes de interés cultural, una cartografía en la que se determine el lugar exacto, pero sí se aprecia una mayor precisión que la otorgada anteriormente a los Lugares de Memoria Histórica ${ }^{44}$.

En 2018, se incoaron (por acuerdo del Consejo de Gobierno de 24 de mayo) y posteriormente se inscribieron (4 de septiembre) otros tres Lugares de Memoria Democrática, dos en Baena (Córdoba) y uno en Puerto Real (Cádiz), con similar método de localización. Estos son, a finales de 2019, los cuatro únicos Lugares de Memoria Democrática de Andalucía declarados (con la tipología de lugares -dos- y de fosas -dos-). La distribución provincial de estos lugares es, dado su escaso número, poco expresiva (uno en Cádiz, dos en Córdoba y uno en Málaga; Figura 4). Ya en enero de 2019 se habían incoado otros nueve lugares (uno en Córdoba, uno en Granada, tres en Jaén, uno en Málaga y tres en Sevilla -ninguno en Almería ni Huelva-; seis construcciones y tres zonas), de forma que solo la fortificación del Estrecho de Gibraltar de los lugares cuya valoración había terminado en julio de 2017 continúa sin tramitación administrativa.

Los Lugares de Memoria Democrática declarados o incoados también se localizan sobre todo en núcleos poblacionales, incluso con una proporción superior a los de Memoria Histórica: 12 en espacios urbanos y dos periurbanos. Tampoco en este caso existe ninguno en un ámbito de dominante natural. En cuanto a la expresión cartográfica de estos lugares, los 13 son puntuales. Solo en el caso de que llegara a incoarse la Fortificación del Estrecho de Gibraltar se contaría con un área que, además de su componente rural, también tiene una importante dominante natural.

44 «Dicho lugar [la esquina del asesinato de Manuel José García Caparrós] se corresponde con la esquina en la vía pública entre la calle Alameda de Colón y el Puente de Tetuán, en la ciudad de Málaga; y se identifica con las coordenadas 36.716548 y -4.425515, según el sistema de medición proporcionado por la aplicación Google Maps», Boletín Oficial de la Junta de Andalucía de 4 de diciembre de 2017. 


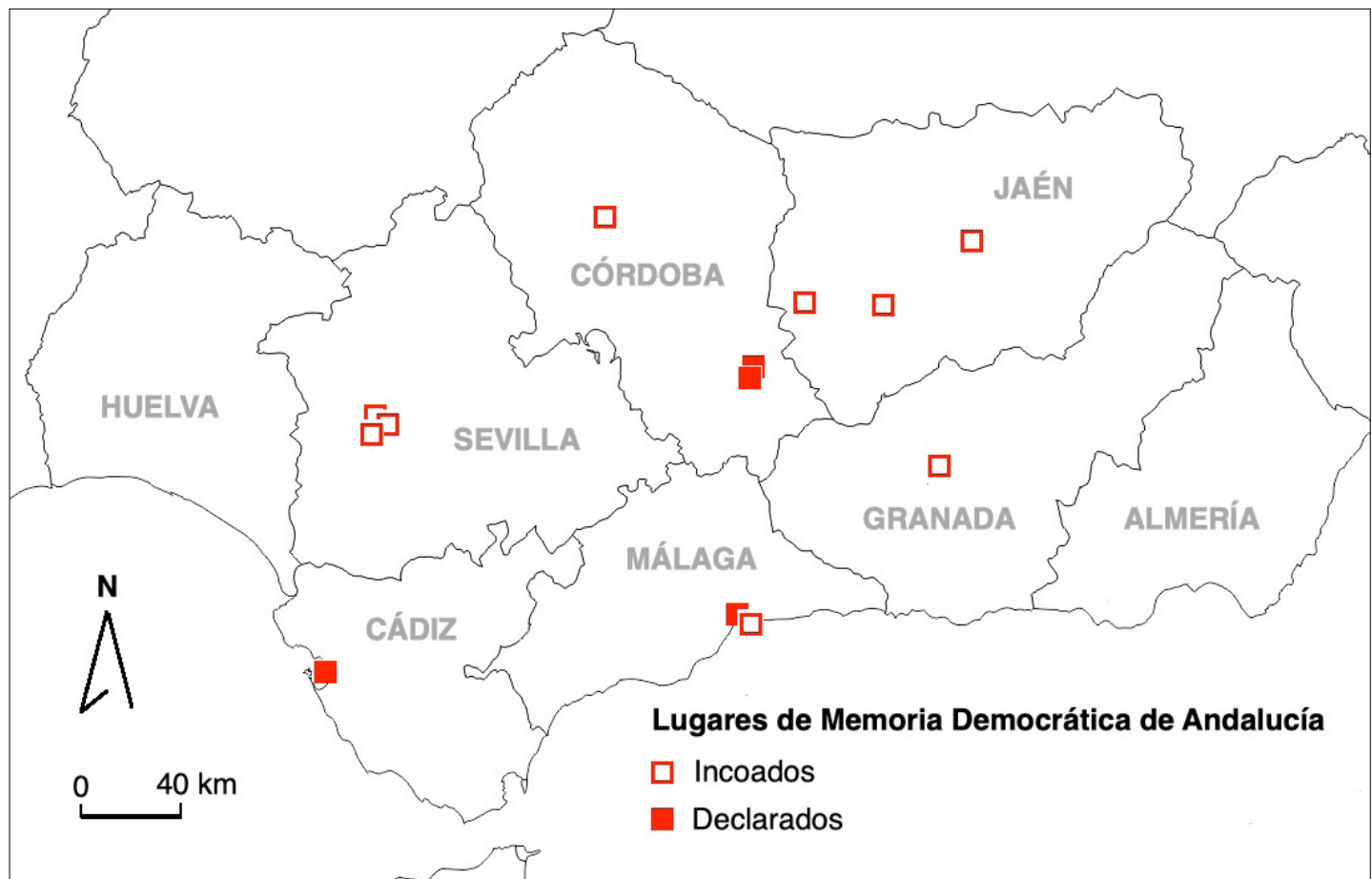

Figura 4. Distribución provincial de los Lugares de Memoria Democrática de Andalucía Fuente: Elaboración propia

Respecto al período en el que se produjeron los hechos rememorados en estos catorce lugares no existe una descripción prolija que emane del acuerdo de gobierno en su fase de valoración. La mayoría ( cinco), de diversa consideración, se relaciona una vez más con hechos acontecidos durante la Guerra Civil; cuatro están relacionados exclusivamente con la Dictadura, y otros tres abarcan guerra y postguerra. Por último, dos están relacionados con dos muertes llevadas a cabo por fuerzas de seguridad durante la Transición.

\section{La iniciativa social y local en la memoria histórica}

\section{Aspectos generales}

Aunque la declaración de los Lugares de Memoria Histórica y de los de Memoria Democrática ha sido y es una competencia de la Junta de Andalucía, no es fácil desentrañar cuantitativamente, pero sí al menos destacar, la responsabilidad que han tenido en este empeño los particulares y organizaciones que, en todo caso, han sido los verdaderos motores del proceso. No es objeto de este artículo detallar la forma en que estos protagonistas han exigido de la administración el impulso a las políticas sobre memoria histórica en Andalucía, pero, sin afán de exhaustividad, deben ser citadas algunas de estas iniciativas. Así, cabría destacar el proyecto Todos (...) los nombres [http://www.todoslosnombres.org], creado en 2005 y cuya base de datos sobre represaliados se acerca a los 100.000 registros personales y casi 1.500 documentos. Otras entidades, cuyo número se aproxima a la cincuentena, tienen un desigual, pero en conjunto, importante peso político y las hay de carácter regional (Asociación Memoria Histórica y Justicia de Andalucía, Asamblea por la Memoria 
Histórica de Andalucía, etc.) y local (Foro por la Memoria del Campo de Gibraltar, Asociación de Represaliados por el Franquismo en la Sauceda y El Marrufo, etc.). La coordinación de estas asociaciones ha pasado por distintas vicisitudes y en abril de 2019 se ha constituido un ente organizativo común. A estas hay que añadir algunas agrupaciones de carácter estatal que también tienen peso específico en Andalucía, entre las que sobresale la Asociación para la Recuperación de la Memoria Histórica (ARMH).

De un modo más institucional, algunos sindicatos han asumido un importante protagonismo en estas reivindicaciones. Así, hay que citar a la Unión General de Trabajadores (U.G.T.), Comisiones Obreras (CC.OO.) o el grupo de trabajo Recuperando la Memoria de la Historia Social de Andalucía de la Confederación General de Trabajadores (CGT). Por último, y con un carácter ya claramente institucional, aunque de significado local, hay que citar el apoyo de muchos ayuntamientos andaluces, muy desigual de unos a otros, y con iniciativas diversas (Oficina de la Memoria Histórica del Ayuntamiento de Sevilla, Oficina Municipal de Memoria Democrática del Ayuntamiento de Cádiz, etc.). Hay que recordar que muchas de las campañas de exhumación de fosas comunes han sido alentadas por las corporaciones locales de la región, entre las que tampoco han faltado las diputaciones.

\section{Las solicitudes sociales y locales de nuevas declaraciones de Lugares de Memoria Democrática de Andalucía}

El Informe de Seguimiento de las Actuaciones en Materia de Memoria Histórica 2017$2018^{45}$ incluye la propuesta de declaración de 36 Lugares de Memoria Democrática

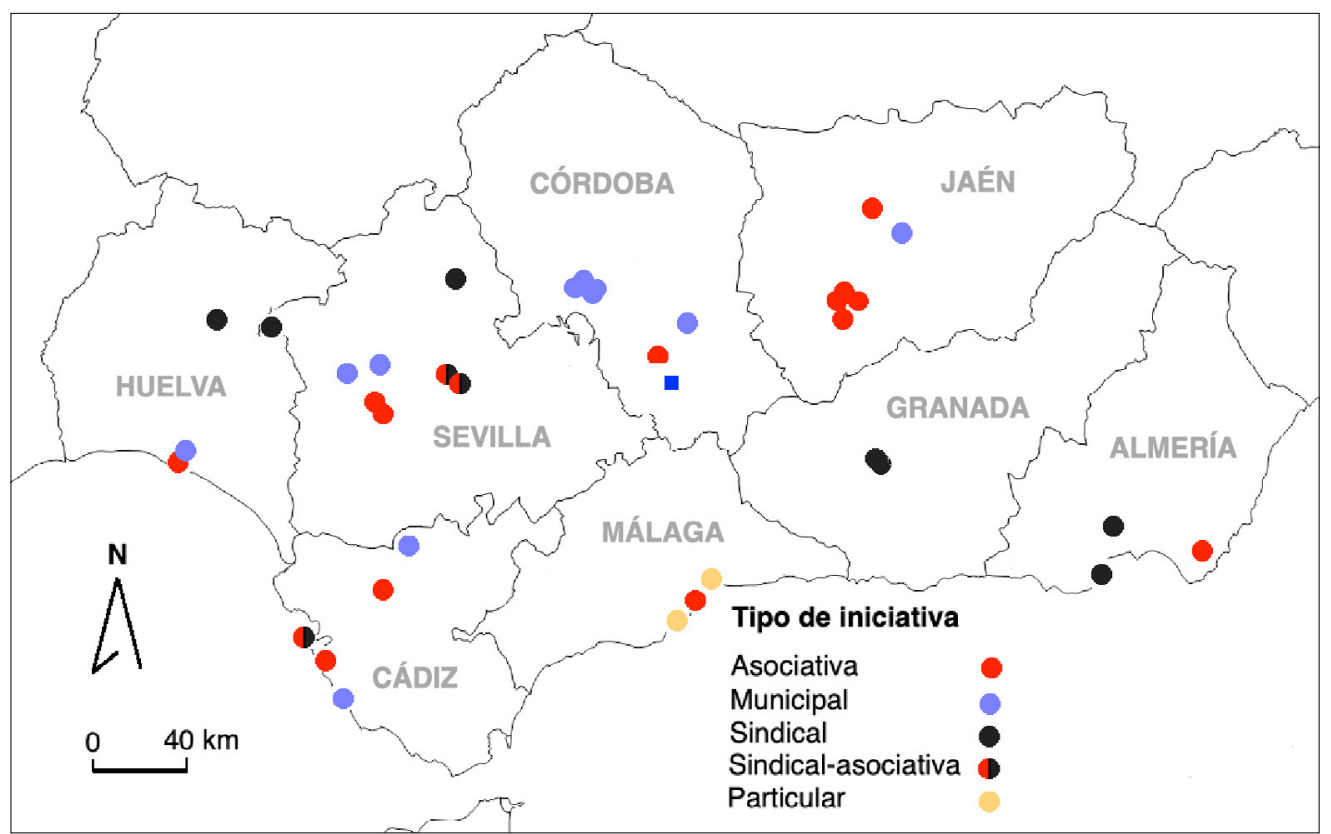

Figura 5. Distribución provincial de las solicitudes sociales y locales de declaraciones de Lugares de Memoria Democrática de Andalucía Fuente: Elaboración propia

45 Consejería de la Presidencia, Administración Local y Memoria Democrática 2019. 
de Andalucía que provienen de bases sociales y locales sensibles a esta política y que aún no se han incoado (Figura 5 y Tabla 6). Es decir, que aunque la recepción de estas propuestas se hace por la Junta de Andalucía, que es la que debe decidir sobre su incoación y, en su caso, declaración, su origen corresponde a la base social La mayoría de ellas proviene de asociaciones (13) y ayuntamientos (11), pero también son activos los sindicatos (7) o mixtas entre estos y asociaciones (3). La tabla la completan 2 de origen particular.

Tabla 6. Solicitudes sociales y locales de declaración de Lugares de Memoria Democrática de Andalucía

\begin{tabular}{|c|c|c|c|c|c|c|c|}
\hline $\begin{array}{l}\text { Lugar objeto de la solicitud } \\
\text { (municipio, provincia) }\end{array}$ & $\stackrel{\circ}{\mathscr{E}}$ & 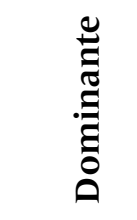 & 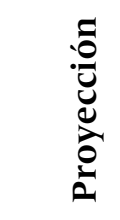 & 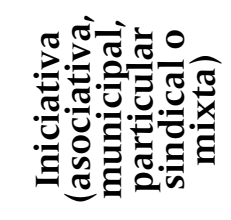 & 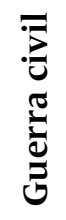 & $\begin{array}{l}\frac{\pi}{3} \\
\frac{\pi}{3} \\
\frac{\pi}{0} \\
\frac{0}{0}\end{array}$ & 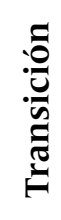 \\
\hline $\begin{array}{l}\text { Antig. Cuartel Casas Fuertes } \\
\text { (Roquetas M, Almer.) }\end{array}$ & Construc. & Rural & Punto & Sindi. & & & $\mathrm{X}$ \\
\hline $\begin{array}{l}\text { Km 8,400 carretera comarcal de } \\
\text { Gergal (Almería) }\end{array}$ & Lugar & Rural & Punto & Sindi. & & & $\mathrm{X}$ \\
\hline $\begin{array}{l}\text { Vestigios Guerra, Cerro La Testa, } \\
\text { Níjar(Almería) }\end{array}$ & Zona & Rural & Área & Asoci. & $\mathrm{X}$ & & \\
\hline $\begin{array}{l}\text { Muro del Cement. Municipal (S. } \\
\text { Fernando, Cádiz) }\end{array}$ & Muro & Urbana & Punto & Asoci. & $X$ & $X$ & \\
\hline Cortijo de Vicos, Jédula, (Cádiz) & Lugar & Rural & Punto & Asoci. & $X$ & $X$ & \\
\hline $\begin{array}{l}\text { Solar de la derribada plaza de } \\
\text { toros (Cádiz) }\end{array}$ & Lugar & Urbana & Punto & Mixta $^{1}$ & $X$ & & \\
\hline $\begin{array}{l}\text { El Granero, Conil de la Frontera } \\
\text { (Cádiz) }\end{array}$ & Construc. & Urbana & Punto & Muni. & $\mathrm{X}$ & & \\
\hline Cárcel vieja de Espera (Cádiz) & Construc. & Urbana & Punto & Muni. & $X$ & & \\
\hline $\begin{array}{l}\text { Cementerio de Aguilar de la Fr. } \\
\text { (Córdoba) }\end{array}$ & Lugar & Urbana & Punto & Asoci. & $\mathrm{X}$ & & \\
\hline $\begin{array}{l}\text { Antiguo economato, } \\
\text { Almodóvar del R. (Córdoba) }\end{array}$ & Construc. & Urbana & Punto & Muni. & $\mathrm{X}$ & & \\
\hline $\begin{array}{l}\text { Fosa cementerio, Almodóvar } \\
\text { del Río (Córdoba) }\end{array}$ & Fosa & Urbana & Punto & Muni. & $X$ & & \\
\hline $\begin{array}{l}\text { Castillo, Almodóvar del Río } \\
\text { (Córdoba) }\end{array}$ & Construc. & Urbana & Punto & Muni. & $X$ & & \\
\hline $\begin{array}{l}\text { Plaza de Abastos, Almodóvar } \\
\text { del Río (Córdoba) }\end{array}$ & Construc. & Urbana & Punto & Muni. & $X$ & & \\
\hline $\begin{array}{l}\text { Centro Obrero, Castro del Río } \\
\text { (Córdoba) }\end{array}$ & Construc. & Urbana & Punto & Muni. & $X$ & & \\
\hline $\begin{array}{l}\text { Lugar asesinato tres } \\
\text { trabajadores (Granada) }\end{array}$ & Lugar & Urbana & Punto & Sindi. & & & $X$ \\
\hline $\begin{array}{l}\text { Comisaría de la plaza de Los } \\
\text { Lobos (Granada) }\end{array}$ & Construc. & Urbana & Punto & Sindi. & & $X$ & $X$ \\
\hline
\end{tabular}



(municipio, provincia)
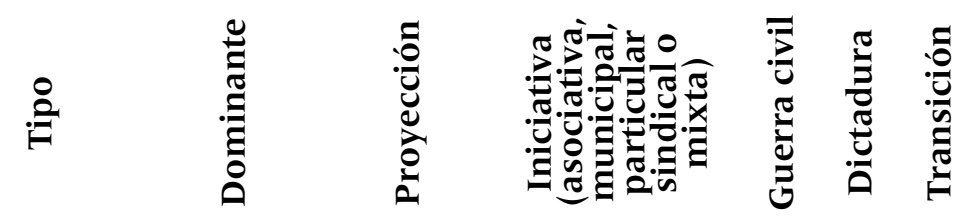

\begin{tabular}{|c|c|c|c|c|c|c|}
\hline $\begin{array}{l}\text { Búnkeres, Punta Malandar, } \\
\text { Mazagón (Huelva) }\end{array}$ & Construc. & Rural & Punto & Asoci. & & $\mathrm{X}$ \\
\hline $\begin{array}{l}\text { Cuesta de la Matita, Palos de la } \\
\text { Fr. (Huelva) }\end{array}$ & Lugar & Rural & Punto & Muni. & $\mathrm{X}$ & \\
\hline $\begin{array}{l}\text { Fosa de La Modestita, Zalamea } \\
\text { la Real (Huelva) }\end{array}$ & Fosa & Rural & Punto & Sindi. & $\mathrm{X}$ & \\
\hline $\begin{array}{l}\text { Fosa común del cementerio, } \\
\text { Baeza (Jaén) }\end{array}$ & Fosa & Urbana & Punto & Muni. & & $\mathrm{X}$ \\
\hline $\begin{array}{l}\text { Refugio y Quirófano Hospit. S. } \\
\text { Juan de Dios (Jaén) }\end{array}$ & Construc. & Urbana & Punto & Asoci. & $\mathrm{X}$ & \\
\hline Convento de Santa Clara (Jaén) & Construc. & Urbana & Punto & Asoci. & & $\mathrm{X}$ \\
\hline $\begin{array}{l}\text { Cementerio de San Eufrasio } \\
\text { (Jaén) }\end{array}$ & Lugar & Urbana & Punto & Asoci. & & $\mathrm{X}$ \\
\hline Aldea de Otíñar (Jaén) & Lugar & Rural & Punto & Asoci. & & $\mathrm{X}$ \\
\hline $\begin{array}{l}\text { Antigua cárcel de Linares - } \\
\text { Pósito- (Jaén) }\end{array}$ & Construc. & Urbana & Punto & Asoci. & & $\mathrm{X}$ \\
\hline $\begin{array}{l}\text { Cementerio viejo, Fuengirola } \\
\text { (Málaga) }\end{array}$ & Lugar & Urbana & Punto & Partic. & $\mathrm{X}$ & \\
\hline Villa Maya (Málaga) & Construc. & Urbana & Punto & Partic. & $\mathrm{X}$ & \\
\hline $\begin{array}{l}\text { Pasaje Begoña, Torremolinos } \\
\text { (Málaga) }\end{array}$ & Lugar & Urbana & Punto & Asoci. & & $\mathrm{X}$ \\
\hline Fosa de Constantina (Sevilla) & Fosa & Periurb. & Punto & Sindi. & $\mathrm{X}$ & \\
\hline $\begin{array}{l}\text { Fosa de El Álamo-El Madroño, } \\
\text { (Sevilla) }\end{array}$ & Fosa & Rural & Punto & Sindi. & $\mathrm{X}$ & \\
\hline $\begin{array}{l}\text { Ant. Cuartel Mil. Dehesa } \\
\text { Matallana (Lora R., Sev.) }\end{array}$ & Construc. & Urbana & Punto & Mixta & & $\mathrm{X}$ \\
\hline $\begin{array}{l}\text { Antigua calera (lugar fusilam.), } \\
\text { Lora R. (Sevilla) }\end{array}$ & Lugar & Periurb. & Punto & Mixta & $X$ & \\
\hline $\begin{array}{l}\text { Fosas del Cementer. de San } \\
\text { Fernando, Sevilla }\end{array}$ & Fosa & Urbana & Punto & Asoci. & $\mathrm{X}$ & $\mathrm{X}$ \\
\hline $\begin{array}{l}\text { Pl. de la Constitución Españ., } \\
\text { Burguillos (Sevilla) }\end{array}$ & Lugar & Urbana & Punto & Muni. & $\mathrm{X}$ & \\
\hline $\begin{array}{l}\text { Pintada Movim. Homosexual } \\
\text { Acción Revol. (Sev.) }\end{array}$ & Construc. & Urbana & Punto & Asoci. & & $\mathrm{X}$ \\
\hline Cementerio de Gerena (Sevilla) & Lugar & Urbana & Punto & Muni. & $X$ & \\
\hline
\end{tabular}

Fuente: Elaboración propia a partir del Informe de Seguimiento de las Actuaciones en Materia de Memoria Histórica 2017-201846. 1 Las declaraciones mixtas son de origen sindical y asociativo.

46 Consejería de la Presidencia, Administración Local y Memoria Democrática 2018, p. 32-33. 
En relación con los tipos de lugares de las solicitudes, hay una cierta variedad; se aprecia que, sobre todo comparados con los Lugares de Memoria Histórica, han descendido las iniciativas ligadas con fosas (6). Entre las solicitudes predominan las referidas a construcciones (15) y a lugares connotados (13), en tanto que no existe ninguna iniciativa de declaración de memoriales, rutas o zonas.

La distribución provincial, al albur de las solicitudes y no de una política redistributiva de las declaraciones, como sucede en casi todas las políticas públicas andaluzas, es bastante irregular y oscila entre las dos solicitudes de Granada y las ocho de Sevilla. Se aprecia una importante concentración entre las provincias de Córdoba, Jaén y Sevilla: entre las tres alcanzan 20 de las 36 solicitudes realizadas.

También las solicitudes de nuevos Lugares de Memoria Democrática de Andalucía se refieren sobre todo a núcleos poblacionales y sus proximidades ( 25 son urbanos y dos periurbanos), pero con una relativa mayor presencia de ámbitos rurales (9). En lo relativo a la proyección cartográfica, esta se vincula mayoritariamente a puntos (35) y solo es reseñable un área: el cerro de la Testa en Níjar por la presencia de vestigios de la Guerra Civil.

La mayor parte de las propuestas se refiere nuevamente al período bélico (20); ocho se relacionan con la Dictadura; tres son mixtas Guerra Civil-Dictadura; cuatro se refieren al período de la Transición y existe una mixta Dictadura-Transición.

Sin embargo, y respecto a estos lugares propuestos, no existe una información actualizada sobre el proceso que llevan sus solicitudes y, en ocasiones, las informaciones son contradictorias. Así, por ejemplo, en mayo de 2018, la prensa local de Jaén ${ }^{47}$ informó de que la Junta de Andalucía había desestimado la propuesta de declaración de Otíñar como Lugar de Memoria Democrática por ser endebles los argumentos que la sustentaban; sin embargo, el Informe de seguimiento de las actuaciones en materia de memoria democrática 2017-2018 presentado a finales de aquel mismo año la seguía manteniendo entre las solicitudes. En otros casos, aunque la propuesta de estudio haya sido asumida para su estudio por la autoridad regional, esto no ha impedido que alguno de estos lugares desapareciese; este es el caso de Villa Maya, residencia del cónsul honorario de México Porfirio Smerdou, lugar que sirvió de refugio a personas de ambos bandos durante la Guerra Civil en Málaga y que fue derribado en marzo de 2019 para la construcción de un chalet ${ }^{48}$.

\section{Conclusiones}

\section{Dudas legales en relación con el período y la determinación de las víctimas en la Ley 2/2017 de Memoria Histórica y Democrática de Andalucía}

En Andalucía, la memoria histórica ha tenido una consideración continuada desde la instauración de la autonomía andaluza por parte de los gobiernos del Partido Socialista Obrero Español (en solitario o en coalición), aunque son los últimos quince años los que marcan actuaciones más decididas; entre ellas las de interpretar y di-

47 La Junta [...], 10 de mayo de 2018.

48 Vázquez, 2019. 
fundir de forma inclusiva la historia de medio siglo de la comunidad autónoma: el período que media entre el 14 de abril de 1931 y el 11 de enero de 1982. Sin embargo, por su necesario engranaje con la ley nacional para el resarcimiento de las víctimas de 2007, no son consideradas como tales las personas que sufrieron menoscabo político durante todo aquel período, sino solo estrictamente las de la Guerra Civil y la Dictadura: del levantamiento militar de 1936 a la entrada en vigor de la Constitución de 1978. Además, el hecho de que en la definición de estas víctimas se aluda a las personas que lucharon en su día por sus derechos y libertades, que sin duda lo merecen, deja al margen, o compromete, a aquellas personas que fueron objeto de algún tipo de menoscabo personal injusto, no pocas veces la pérdida de su vida, sin haber tenido esa actividad proactiva en la consecución y conservación de derechos civiles. También queda indefinida, o simplemente al descubierto del alcance de la ley, la condición de víctimas de aquellos que, por no ser andaluces o no haber tenido la residencia en la comunidad (que es el caso de muchos españoles y de todos los extranjeros), parecen excluidos de aquellos a los que se dirige la ley.

\section{Hacia una regulación normativa mejorada de los sitios de memoria en Andalucía}

Si la emergencia del patrimonio inmaterial está desplazando la finalidad de las políticas patrimoniales desde la protección (concepto objetivo, tradicional y estático) a la salvaguardia (concepto desajustado, contemporáneo y fluido), la memoria histórica, con el devenir dialéctico de su reconocimiento, contribuye a inspirar nuevos contenidos para renovar el concepto de tutela patrimonial. No se trata solo de tramitar declaraciones y de adosar una placa a un muro, que también, sino de generar un ambiente de respeto en torno a lugares que nos explican hoy, como sociedad y como individuos, la herencia de un pasado convulso cuyo presente también alienta el progreso social. Si el lugar de memoria histórica se convierte en un referente identitario, aun con las disensiones sociales que puedan producir las distintas perspectivas políticas, la reflexión patrimonial debe idear nuevas formas con las que estos lugares sean entendidos con el mismo lenguaje que otros bienes culturales cuya legitimidad intelectual y social los haga merecedores de tutela y activación.

El procedimiento de identificar, primero los lugares de Memoria Histórica y, ahora, los de Memoria Democrática, tiene la virtualidad de inspirarse en reivindicaciones de la base social (asociaciones, ayuntamientos, sindicatos y particulares); pero esto desequilibra la expresión territorial del hecho porque, en determinados espacios, la base social reivindicativa es menos potente o porque, dado su carácter rural o natural, no ha tenido valedores ante las instituciones. En consecuencia, deben realizarse revisiones que compensen esta desigualdad.

Aunque la identificación de los Lugares de Memoria Democrática de Andalucía ha mejorado, esta es aún menos precisa que la de otros bienes culturales, especialmente en lo que se refiere a su definición espacial y cartográfica. Además, aunque la Ley de Patrimonio Histórico de Andalucía de 2007 está en proceso de ser renovada, todavía, ni se ha creado el Inventario de Bienes Reconocidos del Patrimonio Histó- 
rico Andaluz (al que debería asociarse el Inventario de Lugares de Memoria Democrática), ni se conoce la forma en que debe implementarse.

Un hecho urgente para evitar el desorden conceptual y administrativo es que se acometa con rapidez la transformación de los Lugares de Memoria Histórica de Andalucía en los de Memoria Democrática, liquidando al efecto el Catálogo de Lugares de Memoria Histórica existente. Además, no se trata solo de una confusión conceptual, sino también de nomenclatura. El cambio en la denominación de histórica por democrática, no solo no aporta nada sustancial al concepto, sino que sigue la línea de las administraciones por cambiar continuamente de nombre a hechos, políticas y taxonomías de las propias instituciones que generan más confusión que claridad. Además, el apelativo de memoria histórica ya es bien entendido por el común de la sociedad (tanto en Andalucía como fuera de ella), en tanto que el de memoria democrática, pese a las buenas intenciones, no se sustenta en un hecho más objetivable, como es la historia, y sí en otro de carácter más simbólico y genérico, como es la democracia, que desenfoca el mensaje y difumina el objeto de aquello que se rememora.

Todavía es pronto para determinar en qué medida la adecuación de los lugares de la Memoria Democrática de Andalucía se realizará de forma coherente con el resto del patrimonio cultural andaluz. En todo caso, es necesario clarificar la consideración legal (que influye en su identificación y protección) de los Lugares de Memoria Democrática. Su pertenencia, de un lado y mayoritaria, al Inventario de Bienes Reconocidos del Patrimonio Histórico Andaluz (por la inclusión en él de los Lugares de Memoria Democrática) o, por otro, al Catálogo General del Patrimonio Histórico Andaluz (cuando sean lugares declarados bienes de interés cultural) plantea un esquema complicado y confuso que puede dificultar el entendimiento y asimilación desde la administración cultural de estos lugares. Parece incongruente que el lugar de nacimiento y el de fusilamiento de Blas Infante, por ser bienes de interés cultural y estar incluidos en el Catálogo General, no puedan formar parte del Inventario de Lugares de Memoria Democrática de Andalucía.

Además, y visto que la memoria histórica posee cada vez más un carácter complejo y poliédrico, cabría preguntarse si su reconocimiento patrimonial no podría también asumir otras figuras que no sean específicamente las del patrimonio inmueble. Parece una contradicción que la memoria, que es un valor intangible, tenga tan poca cabida en los registros del patrimonio inmaterial. Téngase en cuenta, a modo de ejemplo, la cantidad de historias de tradición oral a las que han dado vida las vicisitudes desde la II República a la Transición. Si la Memoria Democrática se inserta en el ámbito de lo patrimonial en Andalucía, debe hacerlo en igualdad de condiciones que el resto de los bienes culturales. Lo que está dificultando este proceso es que ha sido la Ley de Memoria Histórica y Democrática la que ha encontrado al mundo del patrimonio y no al revés. Una vez más, la administración cultural va a la zaga de los cambios sociales. 
También es importante, a efectos del Inventario de los Lugares de la Memoria Democrática, que los sitios inscritos en él sean convenientemente incluidos para su identificación y protección en los catálogos urbanísticos municipales y en los correspondientes planes territoriales y ambientales. Este paso, que exonera a la administración cultural (que se limitará a recopilar la información de protección que le proporcionen) de la protección de estos lugares y que involucra de nuevo a los ámbitos locales desde los que surgieron las propuestas de su reconocimiento institucional, requiere de voluntad política y de pericia técnica innovadora para que su tutela y tratamiento sean los adecuados.

\section{Sobre las declaraciones relacionadas con la memoria histórica en Andalucía: tipos, dominante espacial, proyección cartográfica y etapas históricas}

En lo que concierne a la tipología de los lugares, cabe señalar que, si bien durante las primeras etapas las fosas han sido los registros más numerosos, hecho comprensible por ser uno de las reclamaciones básicas de los familiares de las víctimas, durante los últimos años han cobrado más importancia las construcciones y los lugares connotados. Por su parte, los memoriales y las rutas han perdido relevancia, tanto en los reconocimientos institucionales como en las solicitudes sociales de nuevas inscripciones.

La distribución de los lugares de memoria en Andalucía (incluyendo, tanto los Lugares de Memoria Histórica -50- [Decreto 264/2011], como los de Memoria Democrática - 13-: cuatro declarados y nueve incoados- [Ley 2/2017]), arroja datos bien diferentes en razón de la provincia de que se trate, oscilando entre los tres lugares de la provincia de Almería y los 11 de la de Sevilla. Aunque en su conjunto abarquen el total de la comunidad, la parte suroriental posee menos registros. Esto no quiere decir que la represión haya sido menor allí, sino que los represaliados fueron trasladados en muchas ocasiones a otros lugares o que ha habido menos propuestas de declaraciones. También influyó el hecho de que esta zona oriental permaneciera en el bando republicano hasta el final de la guerra, lo que motivó que la represión allí ejercida fuese de carácter distinto al del resto de Andalucía, incorporada a la fuerza mucho antes en el bando nacional.

Los lugares de memoria analizados son, sobre todo, urbanos; tanto entre los de Memoria Histórica como entre los de Memoria Democrática, no destacando otros espacios que también han tenido un hondo significado (espacios rurales o naturales en los que se produjeron confrontaciones, refugios de maquis, etc.). Es cierto que aún es pronto para valorar cómo se desarrollará la aplicación de la ley en el futuro, pero la tendencia a reforzar lo urbano se mantiene frente a la presencia de lo rural o, incluso, la inexistencia de lo natural.

La distribución de los lugares presentada se combina con una expresión espacial fundamentalmente puntual de estos lugares, especialmente de los de Memoria Democrática, de los que solo una de las solicitudes tiene forma de área. 
Respecto a las etapas históricas a las que se refiere el centenar de Lugares declarados de Memoria Histórica o Democrática o propuestos para tal declaración, cabe señalar que 59 se corresponden con hechos acaecidos durante la Guerra Civil, 19 en la Dictadura y 15 en ambos períodos; uno de ellos abarca también la Transición). A este último período pertenecen seis, más uno que incluye también la Dictadura. La contienda es, como cabría esperar, el período más reiterado en las declaraciones, pero también destaca el hecho de que sean irrelevantes las declaraciones relacionadas con la II República antes del golpe de estado franquista, período convulso en el que sin duda hay hechos significativos que podrían formar parte de los Lugares de Memoria Democrática de Andalucía.

\section{A modo de epílogo}

El desplazamiento político tras la reorganización del Gobierno andaluz a principios de 2019, que traslada la Memoria Democrática de la administración de Presidencia a la de Cultura y Patrimonio Histórico, patrimonializa pero también genera dudas sobre el apoyo con que cuente esta política en un momento clave para el desarrollo de la Ley de 2017 de Memoria Histórica y Democrática de Andalucía. El nuevo poder político andaluz, de sesgo conservador y crítico en el pasado con esa ley, ha manifestado su intención de seguir desarrollándola en su integridad, así como el I Plan de Memoria Democrática 2018-2022. Esto ha supuesto un consenso entre el Partido Socialista Obrero Español y el nuevo gobierno del Partido Popular y Ciudadanos, pese a las protestas del ultraderechista Vox, que también ha entrado en el Parlamento andaluz. Este, para permitir la formación del nuevo gobierno, había exigido la derogación de la ley. Para acallarlos, desde la Consejería de Cultura y Patrimonio Histórico se anuncia el estudio de una futura Ley de Concordia, de la que no se conoce más que su intención de "unir sensibilidades" en palabras de los nuevos dirigentes recogidas en diferentes medios de comunicación. De momento, y para el ejercicio de 2020 se anuncia un recorte muy considerable del presupuesto que preveía el plan. Pero a las dudas que genera la coyuntura política, tal vez deba anteponerse el optimismo: el reconocimiento de la memoria histórica puede ralentizarse, pero tiene difícil vuelta atrás, está en los textos fundamentales que ordenan la vida pública andaluza (al igual que en otras comunidades autónomas, en el Estado y en otros países) y su verificación, justicia y reparación tienen pocos visos de perder fuerza y retroceder como reivindicaciones sociales. Su mensaje, aunque a menudo tenga bases inestables, se ha convertido en global y cada vez es menos cuestionado en el ámbito, no solo de lo políticamente correcto, sino de los códigos que atañen a los derechos humanos, como señalan sin ambages los textos de las Naciones Unidas. En España, además, mientras existan fosas comunes o haya muertos de la Guerra Civil enterrados en las cunetas y descampados, seguirá siendo un debate abierto, apasionado y legítimo. 


\section{Bibliografía}

AGUILAR FERNÁNDEZ, P. La amnesia y la memoria. Las movilizaciones por la amnistía en la transición a la democracia. In PÉREZ LEDESMA, M. y CRUZ MARTÍNEZ, R. Cultura y movilización en la España contemporánea. Madrid: Alianza, 1997, pp. 327-357.

BORTOLOTTO, C. La problemática del patrimonio cultural inmaterial. Culturas. Revista de Gestión Cultural, vol. 1, 2014, p. 1-22. https://polipapers.upv.es/index.php/cs/article/view/3162 [Consulta: 25 de marzo de 2019]

CARDESÍN DÍAZ, J.M. Os lugares da memoria da Guerra Civil na Galica. Grial, vol. 170, p. 44-55. https://www.researchgate.net/publication/261790743_Os_lugares_da_memoria_da_Guerra_ Civil_na_Galiza [Consulta: 12 de diciembre de 2019]

CASTILLO RUIZ, J. El futuro del patrimonio histórico: la patrimonialización del hombre. E-rph, 1, $2007 \mathrm{http} / / /$ revistaseug.ugr.es/index.php/erph/article/view/3313 [Consulta: 22 de febrero de 2019]

CLARK, K. y DRURY, P. Du monument au citoyen: Les fonctions du patrimoine culturel dans une Europe en évolution. In CONSEJO DE EUROPA. Fonctions du patrimoine culturel dans une Europe en changement. Estrasburgo: Conseil de l'Europe, 2002, p. 119-124.

COLMEIRO, J.F. ¿Una nación de fantasmas?: apariciones, memoria histórica y olvidos en la España Postfranquista. $452^{\circ} \mathrm{F}$. Revista electrónica de teoría de la literatura y literatura comparada, vol. 4, 2011, p. 17-34 http://www.452f.com/index.php/es/jose-colmeiro.html [Consulta: 21 de abril de 2019]

\section{CONSEJERÍA DE LA PRESIDENCIA, ADMINISTRACIÓN LOCAL Y MEMORIA}

DEMOCRÁTICA. I Plan Andaluz de Memoria Democrática. 2018-2022. Sevilla: Junta de

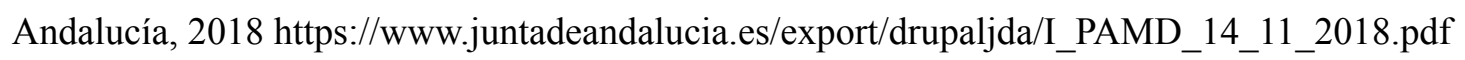
[Consulta: 30 de marzo de 2019]

CRIADO-BOADO, F. y BARREIRO, D. El patrimonio era otra cosa. Estudios Atacameños, vol. 45, 2013 http://dx.doi.org/10.4067/S0718-10432013000100002 [Consulta: 1 de abril de 2019]

CUESTA, J.L. de la y ODRIOZOLA, M. Marco normativo de la memoria histórica en España. Legislación estatal y autonómica. Revista Electrónica de Ciencia Penal y Criminología, vol. 2008, $2018 \mathrm{http} / / /$ criminet.ugr.es/recpc/20/recpc20-08.pdf [Consulta: 25 de marzo de 2019]

GARCÍA ÁLVAREZ, J. Lugares, paisajes y políticas de memoria: una lectura geográfica. Boletín de la Asociación de Geógrafos Españoles, vol. 51, 2009, p. 175-202. age.ieg.csic.es/boletín/51/08GARCIA.pdf [Consulta: 30 de marzo de 2019]

GIL GIL, A. La justicia en transición en España: de la amnistía a la memoria histórica. Barcelona: Atelier, 2009.

GONZÁLEZ VÁZQUEZ, D. Patrimonialización de la memoria histórica: entre el deber social y la estrategia turística. Apuntes sobre el caso catalán. Pasos, vol. 14(5), p. 1267-1280 http://www. pasosonline.org/Publicados/14516/PS516_15.pdf [Consulta: 13 de diciembre de 2019]

HOELSCHER, S. y ALDERMAN, D. Memory and place: geographies of a critical relationships. Social and Cultural Geographies, vol. 5(3), 2004, p. 347-355 https://www.tandfonline.com/doi/ abs/10.1080/1464936042000252769?journalCode=rscg20 [Consulta: 21 de abril de 2019]

La JUNTA desestima la declaración de Otíñar como lugar de memoria histórica, Ideal -ed. Jaén-, 10 de mayo de 2018 https://www.ideal.es/jaen/provincia-jaen/junta-desestima-declaracion20180510011753-nt.html [Consulta: 1 de diciembre de 2019] 
JURADO MARÍN, L. Identidad. Represión hacia los homosexuales en el franquismo. Antequera (Málaga): La Calle, 2014.

LOWENTHAL, D. El pasado es un país extraño. Tres Cantos (Madrid): Akal, 1998 [ed. Original 1985].

MARCOS ARÉVALO, J. La tradición, el patrimonio y la identidad. Revista de Estudios Extremeños, vol. 60 (3), 2004, p. 925-956.

https://dialnet.unirioja.es/servlet/articulo?codigo=1125260\&orden=1\&info=link [Consulta: 10 de diciembre de 2019]

MEDINA DOMÍNGUEZ, A. Exorcismos de la memoria. Políticas y poéticas de la melancolía en la España de la transición. Madrid: Libertarias, 2001.

MÉNDEZ, M.G. Memoria, historia y patrimonio. Hacia una concepción social del patrimonio. Trabajos de Prehistoria, vol. 57(2), 2000, p. 9-20. http://tp.revistas.csic.es/index.php/tp/article/ view/244 [Consulta: 13 de abril de 2019]

MITCHELL, K. Monuments, memorials and the politics of memory. Urban Geography, vol. 24(5), 2003, p. 442-459. https://www.tandfonline.com/doi/abs/10.2747/0272-3638.24.5.442?journalCo $\mathrm{de}=$ rurb20 [Consulta: 3 de mayo de 2019]

MINISTERIO DE EDUCACIÓN, CULTURA Y DEPORTE. Anuario de Estadísticas Culturales 2017. Madrid: Ministerio de Educación, Cultura y Deporte, 2017.

NACIONES UNIDAS. Principios y directrices básicos sobre el derecho de las víctimas manifiestas de las normas internacionales de derechos humanos y de violaciones graves del derecho internacional humanitario a interponer recursos y obtener reparaciones. Resolución 60/47 aprobado por la Asamblea el 16 de diciembre de 2005 https://www.ohchr.org/SP/ ProfessionalInterest/Pages/RemedyAndReparation.aspx [Consulta: 26 de mayo de 2019]

NORA, P. Between Memory and History. Les Lieux de Mémoire. Representations, vol. 26, 1989, p. 7-25 https://www.jstor.org/stable/2928520?seq=1\#page_scan_tab_contents [Consulta: 23 de mayo de 2019]

ORTEGA CANTERO, N. Paisaje, memoria histórica e identidad nacional, Madrid, Universidad Autónoma de Madrid-Fundación Duques de Soria, 2005.

RICOEUR, P. La memoria, la historia, el olvido, Buenos Aires (Argentina), Fondo de Cultura Económica, 2004 [ed. Original 2000]..

RUIZ TORRES, P. Los discursos de la memoria histórica en España. Nova. Revista de Historia Contemporánea, $2007 \mathrm{http} / /$ hispanianova.rediris.es/7/dossier/07d001.pdf [Consulta: 21 de marzo de 2019]

SAHDRA, B. y ROSS, M. Group identification and historical memory", Personality and Social Psychology Bulletin, vol. 33(3), 2007, p. 384-395. https://www.researchgate.net/ publication/6494057_Group_Identification_and_Historical_Memory [Consulta: 20 de mayo de 2019]

SAUCA CANO, J.M. El derecho ciudadano a la memoria histórica: concepto y contenido. In MARTÍN PALLÍN, J.A. y ESCUDERO ALDAY, R. Derecho y memoria histórica, Madrid: Trotta, 2008, p. 73-104. 
SECCIÓN ESPAÑOLA DE AMNISTÍA INTERNACIONAL. España: poner fin al silencio y a la injusticia. La deuda pendiente con las victimas de la Guerra civil española y del régimen franquista, $2005 \mathrm{http}: / /$ www.memoriacatalunya.org/assets/pdf/La\%20deuda\%20pendiente.pdf [Consulta: 1 de abril de 2019]

SILVA PÉREZ, R. Landscape, heritage and territory. Some notes from the Spanish geographic perspective. In Spanish Contribution to 33re IGC Beijing 2016. Spanish Committee International Geographical Union. Madrid: Asociación de Geógrafos Españoles / Instituto Geográfico Nacional / Gobierno de España, 2016, p. 54-62.

SILVA PÉREZ, R. y FERNÁNDEZ SALINAS, V. El nuevo paradigma del patrimonio y su consideración con los paisajes: conceptos, métodos y prospectivas. Documents d'Anàlisi Geogràfica, vol. 63(1), 2017, p. 129-151, https://dag.revista.uab.es/article/view/v63-n1-silvafernandez/344-pdf-es [Consulta: 15 de marzo de 2019]

UNESCO. Convención para la Salvaguardia del Patrimonio Inmaterial. 2003 http://portal.unesco.org/ es/ev.php-URL_ID=17716\&URL_DO=DO_TOPIC\&URL_SECTION=201.html [Consulta: 1 de abril de 2019]

VAZQUEZ, J. Derriban Villa Maya, histórico refugio de malagueños de ambos bandos en la Guerra Civil. La Opinión de Málaga, 19 de marzo de 2019, https://www.laopiniondemalaga. es/malaga/2019/03/19/derriban-villa-maya-historico-refugio/1075644.html [Consulta: 29 de noviembre de 2019]

VERDIER, N. La memoria de los lugares: entre espacios de la historia y territorios de la geografía. In ORTEGA CANTERO, N.; GARCÍA ÁLVAREZ, J. y MOLLÁ RUIZ-GÓMEZ, M. Lenguajes y visiones del paisaje y del territorio. Madrid, Universidad Autónoma de Madrid, 2010, p. 209-217 https:/halshs.archives-ouvertes.fr/halshs-00517715/document [Consulta: 21 de marzo de 2019]

YESTE, E. La transición española. Reconciliación nacional a cambio de desmemoria. El olvido público de la guerra civil. Historia Actual Online, vol. 21, 2010, p. 7-12. https://dialnet.unirioja. es/servlet/articulo?codigo=3193650 [Consulta: 30 de abril de 2019]

(C) Copyright: Víctor Fernández Salinas y Rocío Silva Pérez, 2020

(c) Copyright: Scripta Nova, 2020.

Ficha bibliográfica:

FERNÁNDEZ, Victor; SILVA, Rocío. Conmemoración, patrimonio y espacio. Los lugares de memoria histórica y democrática de Andalucía. Scripta Nova. Revista Electrónica de Geografía y Ciencias Sociales. Barcelona: Universidad de Barcelona, 15 de Agosto de 2020, vol. XXIV, $\mathrm{n}^{\mathrm{o}}$ 644. [ISSN: 1138-9788] 